\title{
The impact of current and possibly future sea surface temperature anomalies on the frequency of Atlantic hurricanes
}

\section{T.N. Krishnamurti, Ricardo Correa-Torres, Mojib Latif \& Glenn Daughenbaugh}

To cite this article: T.N. Krishnamurti, Ricardo Correa-Torres, Mojib Latif \& Glenn Daughenbaugh (1998) The impact of current and possibly future sea surface temperature anomalies on the frequency of Atlantic hurricanes, Tellus A: Dynamic Meteorology and Oceanography, 50:2, 186-210, DOI: $10.3402 /$ tellusa.v50i2.14520

To link to this article: https://doi.org/10.3402/tellusa.v50i2.14520

\section{(C) 1998 The Author(s). Published by Taylor \& Francis.}

\section{曲 Published online: 15 Dec 2016.}

Submit your article to this journal 2

III Article views: 143

Q View related articles $\square$

47 Citing articles: 3 View citing articles 준 


\title{
The impact of current and possibly future sea surface temperature anomalies on the frequency of Atlantic hurricanes
}

\author{
By T. N. KRISHNAMURTI, ${ }^{1, *}$ RICARDO CORREA-TORRES ${ }^{1}{ }^{1}$ MOJIB LATIF ${ }^{2}$ and GLENN \\ DAUGHENBAUGH ${ }^{1},{ }^{1}$ Department of Meteorology, Florida State University, Tallahassee, FL 32306, \\ USA. ${ }^{2}$ Max Planck Institut für Meteorologie, Hamburg, D-20146, Germany
}

(Manuscript received 19 December 1996; in final form 3 November 1997)

\begin{abstract}
A brief summary of the current capabilities of a high resolution global numerical prediction model towards resolving the life cycles of hurricanes is first presented. Next, we illustrate the results of season long integrations for the years 1987 and 1988 using the observed sea surface temperature (SST) anomalies over the global oceans. The model being used here is the FSU atmospheric global spectral model at the horizontal resolution of T42 and with 16 vertical layers. The main emphasis of this study is on hurricane tracks for these and for global warming experiments. The global warming scenarios were modeled using doubled $\mathrm{CO}_{2}$ and enhanced SST anomalies. The model being atmospheric does not simulate the ocean, and SST anomalies need to be prescribed. It is assumed in these experiments that the SST anomalies of the doubled $\mathrm{CO}_{2}$ world appear similar to those of the current period but that they are slightly warmer over the global tropics. That is determined using a simple proportionality relationship requiring an enhancement of the global mean SST anomaly over the tropics. Such an enhancement of the SST anomaly of an El Niño year 1987 amplifies the SST anomaly for the El Niño of the double $\mathrm{CO}_{2}$ atmosphere somewhat. The La Niña SST anomalies were similarly enhanced for the double $\mathrm{CO}_{2}$ atmosphere during 1988. These hurricane season experiments cover the period June through October for the respective years. It was necessary to define the thresholds for a model simulated hurricane; given such a definition we have compared first the tracks and frequency of storms based on the present day $\mathrm{CO}_{2}$ simulations with the observed storms for 1987 and 1988. Those comparisons were noted to be very close to the observed numbers of the storms. The doubled $\mathrm{CO}_{2}$ storms show a significant enhancement of the frequency of storms for the La Niña periods, however there was no noticeable change for the El Niño experiments. We have also run an experiment using the SST anomalies from a triple $\mathrm{CO}_{2}$ climate run made at the Max Planck Institut at Hamburg. This experiment simulated some 7 hurricanes over the Atlantic Ocean. The intensity of hurricanes, inferred from maximum winds at $850 \mathrm{mb}$, show that on the average the storms are slightly more intense for the double $\mathrm{CO}_{2}$ experiments compared to the storms simulated from current $\mathrm{CO}_{2}$ conditions. The triple $\mathrm{CO}_{2}$ storms were slightly stronger in this entire series of experiments.
\end{abstract}

\section{Introduction}

In this paper we examine the issue of seasonal hurricane forecasts in the context of climate models

\footnotetext{
* Corresponding author.
}

of the current and future global warming scenarios. This study follows the recent investigations of Broccoli and Manabe (1990), Haarsma et al. (1993), Emanuel (1987, 1988, 1991), and Tsutsui and Kasahara (1996). As has been noted by Emanuel, "Tropical cyclones rank with earthquakes as the 
major geophysical causes of loss of life and property." It is therefore of practical as well as scientific interest to estimate the changes in tropical cyclone frequency and intensity that might result form shortterm, man-induced alterations of the climate. This is a relevant issue for modeling.

Broccoli and Manabe (1990), in their pioneering work on this problem, demonstrated a significant increase in the number of storm days when they used an interactive cloud radiation scheme in double $\mathrm{CO}_{2}$ experiments at two different resolutions. They noted a 16 to $19 \%$ increase in the number of storm days for both models. Some of their other experiments, where the interactive clouds were replaced by fixed clouds, were inconclusive with respect to storm frequency and hurricane days.

Haarsma et al. (1993) examined the issue of tropical storms in a double $\mathrm{CO}_{2}$ environment using a coupled atmosphere-ocean model. Under the current $\mathrm{CO}_{2}$ conditions, their simulations of the seasonal hurricane track climatology resembles closely those from Gray's (1968) study. Despite their weak intensity, the tropical disturbances in Haarsma's study provided a reasonable simulation of the geographical distribution over the Pacific and Indian Oceans. The central and the eastern Atlantic Ocean were somewhat less active, but the distribution was closer to the climatology over the western Atlantic especially the Caribbean Sea.

In two recent important papers, Bengtsson et al. $(1995,1996)$ have explored the issue of hurricane simulation in climate models. In the first of these papers they examine the capabilities of an atmospheric climate model under the current atmospheric $\left(\mathrm{CO}_{2}\right)$ conditions using a horizontal resolution of 106 waves (triangular truncation) and 19 vertical levels. Their simulation shows an essential agreement with the observational knowledge of the hurricane statistics. In the second paper they addressed the issue of the hurricanes of the future. The SST's for these experiments were first obtained from a low resolution coupled atmospheric-ocean model; these were next used in an atmospheric model at the resolution of T106. They drew a major conclusion that the number of storms were significantly reduced under the enhanced $\mathrm{CO}_{2}$ conditions. They allude these results to a weakening of the Hadley cell and to an intensification of upper-level westerlies.
Emanuel (1986) developed a simple relationship between the maximum possible pressure drop within the eye of a hurricane as a function of sea surface temperature. This theory is based on a Carnot cycle model under an assumption of constant relative humidity (near $85 \%$ ) for both the current and the double $\mathrm{CO}_{2}$ scenarios. Although this analysis does not claim to address the storm frequency, Emanuel states only that "there is no obvious reason, however to suppose that frequencies would be substantially diminished in a climate with doubled $\mathrm{CO}_{2}$."

The present study belongs to the same class of studies as those cited above. We shall first describe the performance of a high resolution global numerical prediction model in the context of the prediction of the hurricane's life cycle. We shall next adopt this model towards seasonal hurricane simulations in the climate modeling context. Here we shall address the capabilities of the model for seasonal prediction for the present as well as for plausible future global warming scenarios. A motivation for this study is to explore if, in future scenarios of double $\mathrm{CO}_{2}$, we can expect to see some distinction among the distribution of Atlantic hurricanes during El Niño and La Niña years.

\section{The FSU atmospheric global spectral model}

This model has been used previously on a number of studies of hurricanes. Some of the salient results from these previous studies are summarized below. An outline of the components of this model is presented in the Appendix. This model utilizes the spectral transform method which has been run at very high horizontal resolutions such as T170 and T213 in most of the previous hurricane prediction studies, although for this study a resolution of T42 was used. It uses a semi-implicit time differencing algorithm. This model includes a detailed array of parameterization for the physical processes such as interactive cloud radiation with a detailed surface energy balance with diurnal changes, cumulus parameterization, shallow and dry convective processes, surface fluxes of momentum, heat and moisture within detailed ocean and land surface processes, inclusion of mountains, effects of snow and ice cover on surface fluxes and radiative interactions, and a detailed model initialization. 
The modeling of double $\mathrm{CO}_{2}$ storms requires a demonstration that the model is capable of predicting current day storms reasonably on the medium range time scale of the order of a week. Furthermore it is perhaps also desirable that the model have some reasonable statistics for the storm count and possibly on the location of storms for its seasonal prediction. The FSU global spectral model has been used to study the life cycle of numerous storms over the Atlantic, Pacific and the Indian Ocean basins. A few of these earlier results are briefly described here. The model successfully handled a case of tropical cyclone formation (Hurricane Frederic of 1979). Fig. 1 shows the isotachs of the lower tropospheric motion field and their evolution over a 72-h period. Full results and discussion are found in Krishnamurti et al. (1994a). The FSU global spectral model successfully handled the life cycle of a super typhoon (Hope of 1979, Krishnamurti et al., 1989a and 1989b). The FSU global spectral model also successfully predicted the landfall of the recent (April, 1991) devastating tropical cyclone of Bangladesh (Krishnamurti et al., 1994b). Similar success was seen with Hurricane Andrew of 1992 (Krishnamurti et al., 1995a) and its landfall over Homestead AFB in South Florida, USA. Successful experiments have also been completed for multiple tropical cyclone cases (Krishnamurti et al., 1993) such as the triple typhoon case over the Pacific Ocean in September of 1987. Finally, the FSU global spectral model has successfully predicted tropical cyclone recurvature dynamics and scenarios. Krishnamurti et al. (1992) examined the recurvature dynamics of several typhoons over the Pacific Ocean. This same model has also been used for these seasonal projections.

\section{Seasonal hurricane simulations}

We shall next address the capability of the above global model for seasonal hurricane

FREDERIC T170 FCST WIND SPEED $850 \mathrm{hPa}$

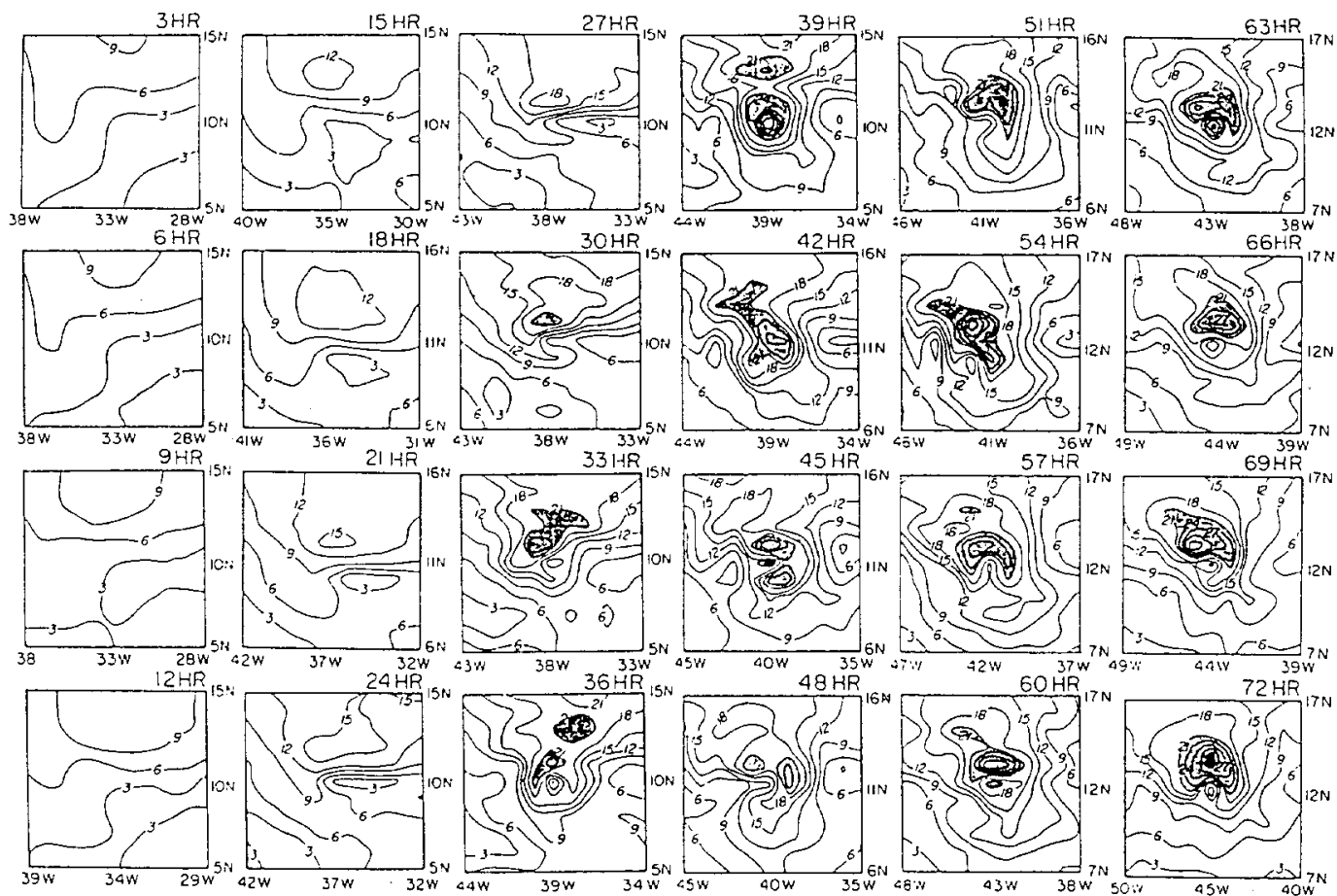

Fig. 1. $850 \mathrm{hPa}$ isotachs $\left(\mathrm{ms}^{-1}\right)$ during the formation of hurricane Frederic of 1979 . The model run is at the resolution T170, from Krishnamurti et al. (1994). 
simulations. Using current estimates of $\mathrm{CO}_{2}$, and observed sea surface temperature anomalies and satellite observations of snow and ice cover, we have first carried out two (hurricane) season long integrations for an El Niño year 1987 and a La Niña year 1988. For these experiments, we made use of the European Centre for Medium-Range Weather Forecasts (ECMWF) analysis to define the initial state, i.e. June 1st of the respective years. The global model was integrated at a resolution of T42 for these experiments. That is a rather coarse resolution to resolve a hurricane; however, as we shall see from Sub-ection 7.2, we can simulate rather respectable looking warm core storms, albeit too large in size. All of these integrations cover an entire hurricane season, i.e. June through November. In the radiative transfer code we include absorption by $\mathrm{CO}_{2}, \mathrm{O}_{3}$ and water vapor. Whereas water vapor is a dependant variable of the model, the distribution of $\mathrm{CO}_{2}$ and $\mathrm{O}_{3}$ are derived via tabular constants. Those values of $\mathrm{CO}_{2}$ were doubled or tripled for the double and the triple $\mathrm{CO}_{2}$ experiments respectively.

\subsection{On the definition of a hurricane in a climate model}

Although the hurricanes in the global model at the resolution of T42 are very clearly defined, it is necessary to contrast between weaker tropical storms from the more intense systems. Most climate modellers, who have addressed the formation of hurricanes have invoked a useful definition for the model hurricane. Here we have adopted a definition based on the recent studies of Bengtsson et al. $(1995,1996)$.

Model Hurricane Criteria:

- Relative vorticity at $850 \mathrm{hPa}>3.5 \times 10^{-5} \mathrm{~s}^{-1}$.

- A maximum velocity (at $850 \mathrm{hPa}$ ) of $15 \mathrm{~ms}^{-1}$ (at least) and a minimum surface pressure within a $4 \times 4$ grid-point area around the point which fulfills condition 1 .

- The sum of the temperature anomalies (derivation from the mean, which consists of the $4 \times 4$ grid points) at 700,500 , and $300 \mathrm{hPa}>3 \mathrm{~K}$.

- The temperature anomaly at $300 \mathrm{hPa}>$ temperature anomaly at $850 \mathrm{hPa}$.

- The mean wind speed at $850 \mathrm{hPa}>$ mean wind speed at $300 \mathrm{hPa}$.
- Minimum duration of the event (the previous five criteria) $>$ or $=24 \mathrm{~h}$.

\section{The sea surface temperature anomaly fields}

In this section, we shall describe the sea surface temperature fields that were used for the current and the future global warming scenarios.

\subsection{SST anomalies for the current and double $\mathrm{CO}_{2}$ experiments}

The basic SST anomaly (SSTA) data sets came from the National Oceanic and Atmospheric Administration (NOAA) Climate Analysis Center in Washington, D.C. These are the 10 day averages blended, or the so called Reynold's SST fields. This basic data covered the period 1 June through 31 October for the El Niño year 1987 and the La Niña year 1988. These were linearly interpolated to every time step of the global model.

Following Manabe and Stouffer (1994) we shall assume that SSTA's during global warming would still continue to exhibit the comings and goings on of the El Niño and La Niña. We shall furthermore assume that the differences in SSTA between the El Niño and the La Niña would not be enhanced during the global warming.

We define a set of new SSTA for the global warming scenarios by the relation $\mathrm{SSTA})_{\mathrm{GW}}=$ $\mathrm{SSTA}+\varepsilon|\mathrm{SSTA}|+0.5 \mathrm{~K}$ where SSTA) $)_{\mathrm{Gw}}$ is the local value of the sea surface temperature anomaly for the global warming, i.e., the $2 \times \mathrm{CO}_{2}$, experiment. SSTA denotes the sea surface temperature anomaly of a current (El Niño or a La Niña) year. A correction term based on the absolute value of the current SSTA utilizes a constant of proportionality $\varepsilon$ which was determined from a relation,

$\varepsilon=0.5 / \frac{1}{N} \sum_{i=1}^{N}|\mathrm{SSTA}|$,

where $N$ denotes the number of oceanic grid points over the tropical belt between $32^{\circ} \mathrm{S}$ and $32^{\circ} \mathrm{N}$, or

$$
\mathrm{SSTA})_{\mathrm{GW}}=\mathrm{SSTA}+\varepsilon|\mathrm{SSTA}|+0.5^{\circ} \mathrm{K}
$$

Thus the SSTA's are enhanced by a positive definite value proportional to the absolute value of the local SSTA. Furthermore, over the entire tropics the mean value of SSTA is enhanced by 
$0.5^{\circ}$. Thus the cold phase would not be as cold and the warm phase would be warmer for the $2 \times \mathrm{CO}_{2}$ experiments compared to the current SSTA.

The mean differences between the SSTA between El Niño and La Niña phases are preserved for the $1 \times \mathrm{CO}_{2}$ and the $2 \times \mathrm{CO}_{2}$ experiments. In the mean the SSTA over global tropical oceans are $1 / 2 \mathrm{~K}$ warmer for the $2 \times \mathrm{CO}_{2} \mathrm{com}$ pared to the $1 \times \mathrm{CO}_{2}$. We shall next illustrate the sea surface temperature fields.

(a) El Niño year: Figs. 2a, 3a illustrates the SST anomalies for the El Niño year 1987 and for the corresponding enhanced geometry for the double
$\mathrm{CO}_{2}$ El Niño year. We note the following features. The SST anomaly (averaged for the entire hurricane season June through October 1987) exhibits warm SST's over the equatorial eastern Pacific Ocean of the order of 1 to $2 \mathrm{~K}$. Over that same region the $\mathrm{El}$ Niño warming is considerably enhanced for the double $\mathrm{CO}_{2}$. The maximum value of the SSTA over the equatorial central Pacific Ocean is of the order of $3 \mathrm{~K}$. Here, we are prescribing a more intense El Niño SSTA for this double $\mathrm{CO}_{2}$ as compared to the single $\mathrm{CO}_{2}$. Over the tropical Indian Ocean, the SSTA is enhanced from 1 to $2 \mathrm{~K}$ from the single to the double $\mathrm{CO}_{2}$. A similar enhancement is also noted over the
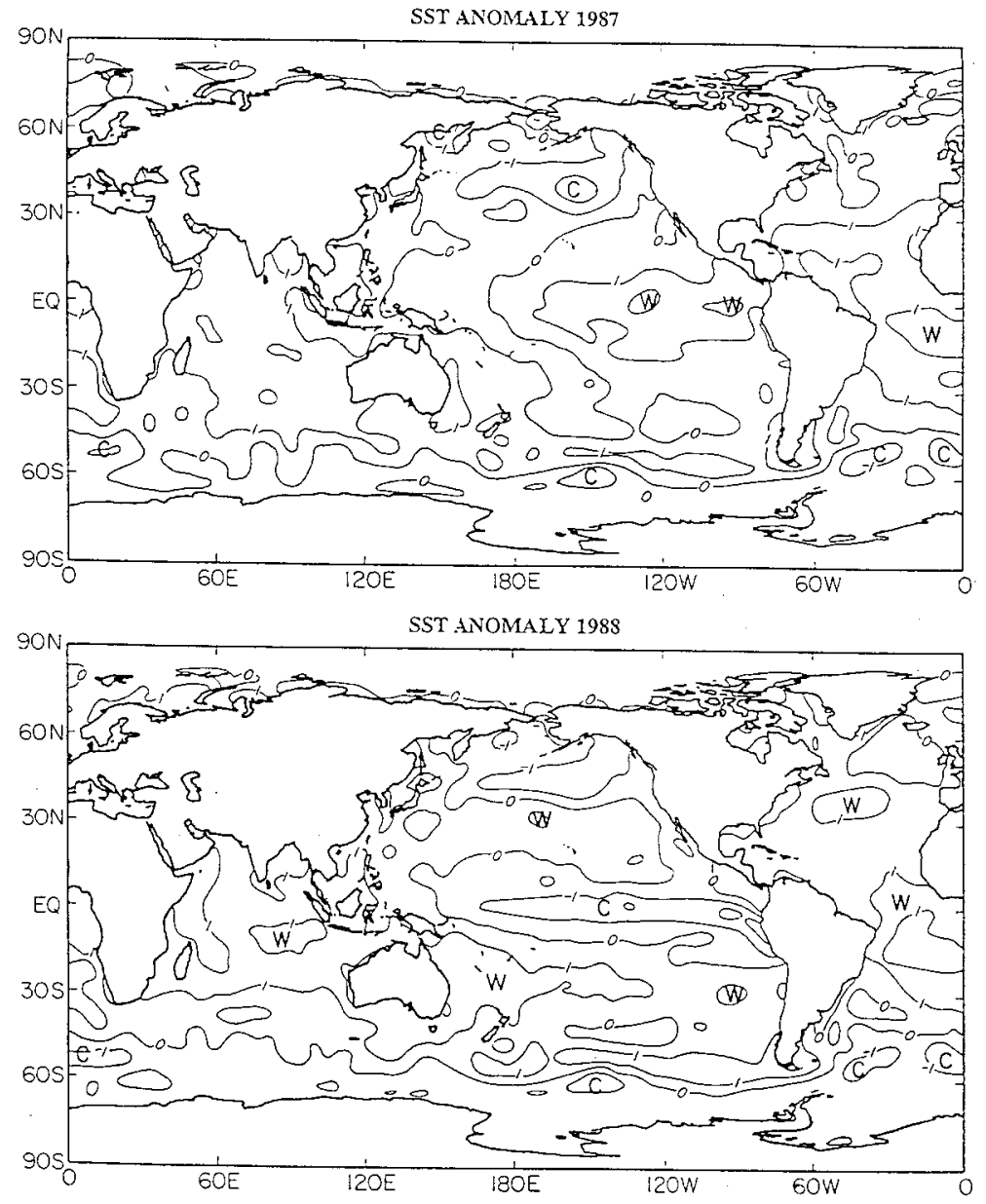

Fig. 2. Sea surface temperature anomaly fields for the hurricane season 1 June through 31 October. These fields are obtained from the NMC operational 10 day mean data sets. Units K. (a) 1987 (El Niño year); (b) 1988 (La Niña year). 

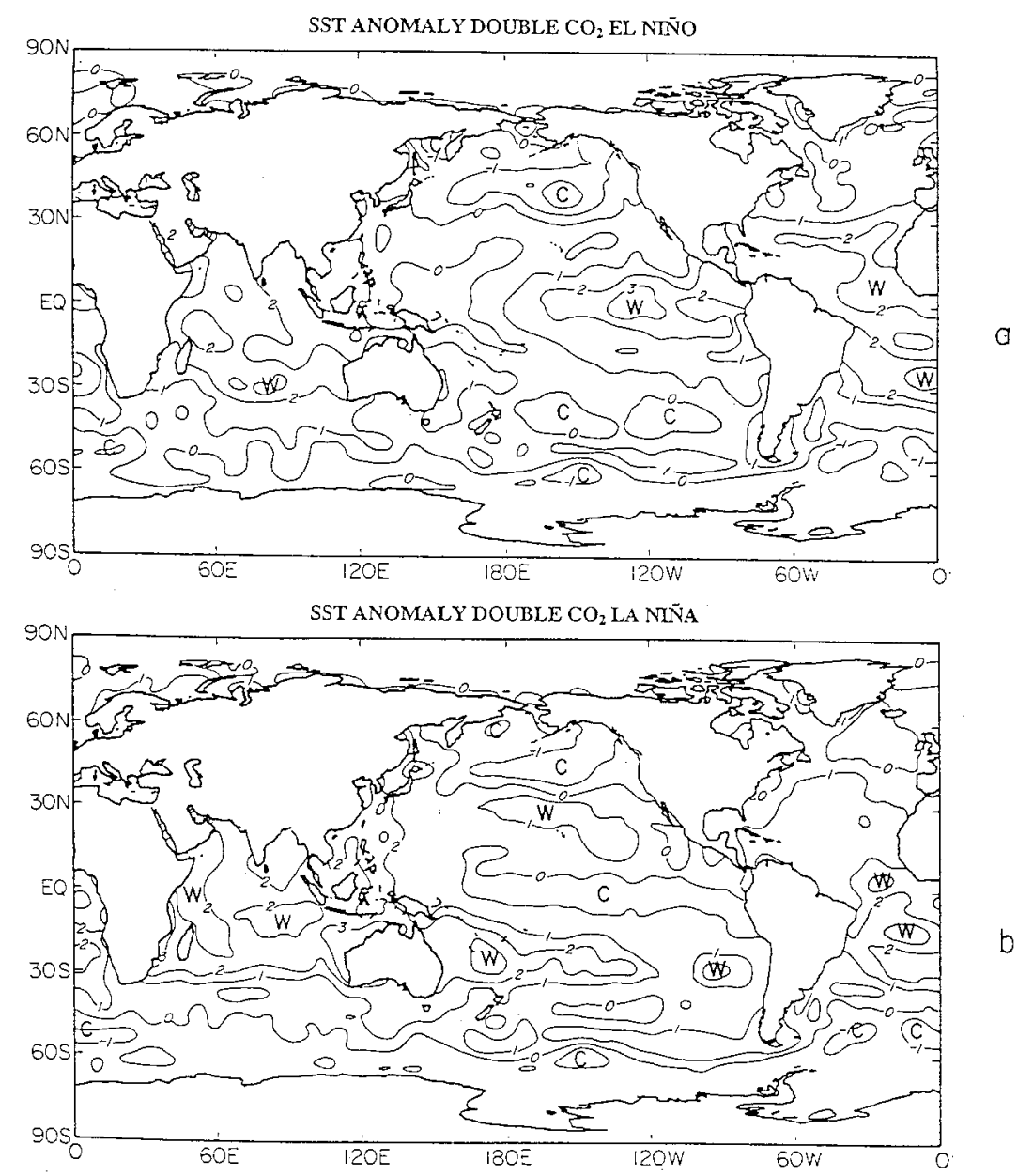

Fig. 3. Sea surface temperature anomaly fields for the double $\mathrm{CO}_{2}$ experiments. These are obtained by modifying the observed anomalies of Fig. 8 requiring tropical oceanic warming of $0.5 \mathrm{~K}$. (a) El Niño; (b) La Niña.

tropical Atlantic Ocean. The southern tropical Atlantic Ocean also sees an enhanced warm SSTA $(\approx 2 \mathrm{~K})$ under this prescription. Over most other oceanic regions the changes in SSTA are less than $1 \mathrm{~K}$.

(b) La Niña year: Here the two SST fields for the single and the double $\mathrm{CO}_{2}$ experiments are illustrated in Figs. 2b, 3b. The cold phase with the SSTA somewhat colder than $-1 \mathrm{~K}$ are noted over the equatorial Pacific Ocean for the year 1988 The prescription for the double $\mathrm{CO}_{2}$ makes the SST anomalies somewhat warmer than $-1 \mathrm{~K}$ over this region, Fig. (3b). The tropical Atlantic exhibits SSTA of the order of $1 \mathrm{~K}$ for the year 1988. These are enhanced by roughly a degree for the double $\mathrm{CO}_{2}$ experiment. That difference was one of the important factors in the hurricane climatology of the Atlantic Ocean.

It should be stated that the day to day integration does not see these SST anomalies directly. What is provided as a lower boundary condition to the model are the 10 day averaged SST anomalies and the enhanced SST anomalies for the global warming. That 10 day averaged field of SST anomaly has considerable variability compared to these seasonal averages and have a different impact on the storm formation at different periods.

Tellus 50A (1998), 2 


\subsection{The SST anomalies from a Hamburg coupled atmosphere-ocean experiment}

The Hamburg coupled atmosphere-ocean model, (Cubasch et al., 1992), was recently run for an extended period by the Hamburg group with a gradually increasing $\mathrm{CO}_{2}$. That increase mimicked the observed rate of increase of $\mathrm{CO}_{2}$ as seen from the Mauna Loa data and projected on to the future. That experiment was terminated at three times the current $\mathrm{CO}_{2}$ levels. The surface temperature anomalies from that coupled model were used as another SSTA for our series of experiments. Fig. 4 illustrates this field of the surface temperature of the Hamburg experiment. These are anomalies with respect to current day seasonal climatology. This shows two lobes of warm SST anomalies of the order of $2 \mathrm{~K}$ on either side of the equator. The tropical Atlantic Ocean shows warm anomalies of approximately 1.5 to $2 \mathrm{~K}$ in the hurricane belt. The Indian Ocean also reflects a similar warming. A surprising feature here are the warm anomalies near $30^{\circ} \mathrm{S}$ over the Indian and the Pacific Ocean.

\section{Spin up of the model}

In order to equilibrate our model to the double and triple $\mathrm{CO}_{2}$ environments, it was necessary to run the model initially for an extended period. After discussion with Dr. Syukuro Manabe (personal communication) it was decided to initiate a spin up period of 6 months. The experiment for the years 1987 and 1988 were spun up using the 1 June start date for the respective years. A 6-month spin up with a fixed zenith angle was necessary for these experiments. For the triple $\mathrm{CO}_{2}$ experiment, data was available from 1 December of the year before the simulation year; that experiment was spun up for a long time from 1 December through 1 June of that data set. In this triple $\mathrm{CO}_{2}$ experiment no additional updates of data, other than SST, were used. The 6 month period permits a new radiative convective equilibrium to be realized under the enhanced $\mathrm{CO}_{2}$ configurations. The moist adiabats over the tropics, in particular, are shifted towards somewhat warmer temperatures and the retention

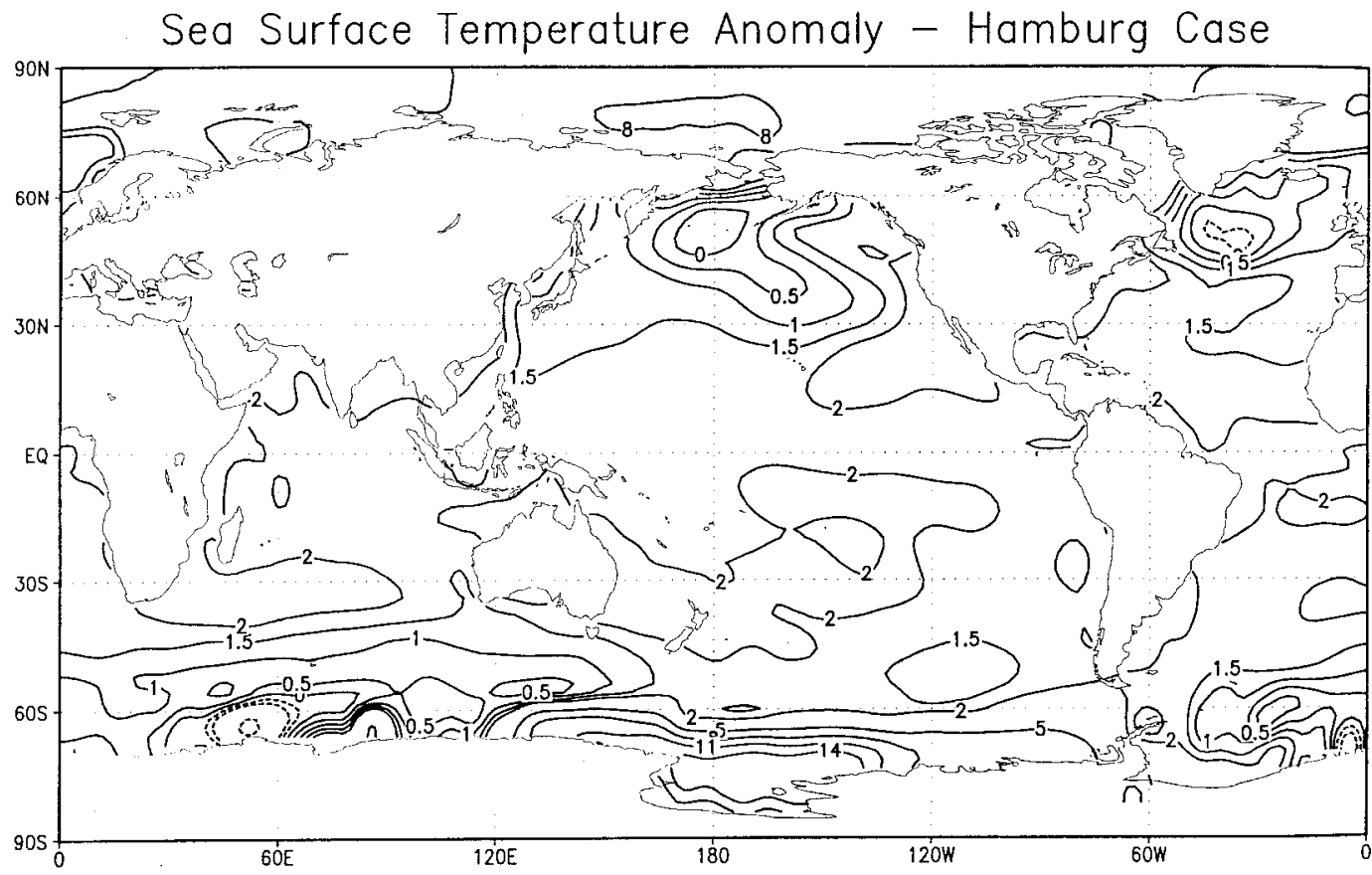

Fig. 4. SST anomalies from a triple $\mathrm{CO}_{2}$ coupled ocean-atmosphere model run made at the Max-Planck Institut at Hamburg. Units: K. 
of water vapor (via the increased saturation specific humidity), in the atmosphere is somewhat enhanced during this spin up.

\section{Results of computations}

We shall not describe the details of the seasonal simulations for the 1987 and 1988 (single $\mathrm{CO}_{2}$ ) experiments. Those are presented in some detail in 2 recent papers, Krishnamurti et al. (1995b, 1996).

\subsection{The Caribbean monsoon trough, an important feature of the double $\mathrm{CO}_{2}$ experiments}

The time-mean flows at $850 \mathrm{hPa}$ for the hurricane season (June through October), based on observations, and the single and double $\mathrm{CO}_{2}$ experiments for the La Niña year are presented in Fig. 5. Oceanic monsoon troughs have been known to be breeding grounds for typhoons. That is a well known feature in the circulation of the Western Pacific Ocean. A monsoon trough over the ocean is usually a zonally elongated cyclonic trough of the lower troposphere whose major axis is located roughly near 7 to $10^{\circ} \mathrm{N}$ (Sadler and Harris, 1970). Imbedded within the trough may lie several closed cyclonic disturbances. The equatorward side of this trough is characterized by monsoon westerlies; trade wind easterlies are found to be the north of the monsoon trough. Flow features of this type have also been noted in the eastern Pacific Ocean (Emanuel, 1993). Some typhoons of the western Pacific and hurricanes of the eastern Pacific have been known to form on the poleward side of the monsoon trough. The eastern Pacific monsoon trough is not known to extend eastwards into the Caribbean sea or the eastern Atlantic Ocean. The seasonal simulations for the single $\mathrm{CO}_{2}$ experiments for the El Niño and the La Niña years did not exhibit such a monsoon trough over the Caribbean. It was during the La Niña year of the double $\mathrm{CO}_{2}$ experiments that we noted a prominent monsoon trough. An excessive number of storms that formed in this double $\mathrm{CO}_{2}$ experiment were related to this monsoon trough.

\subsection{Sample Storms of the $1 \times \mathrm{CO}_{2}$ and $2 \times \mathrm{CO}_{2}$ modeling experiments}

Figs. 6a, $\mathrm{b}$ illustrate a sequence of flow charts at the $850 \mathrm{hPa}$, modeled, during the life cycles of a modeled hurricane under future $\left(2 \times \mathrm{CO}_{2}\right)$ and the current $\left(1 \times \mathrm{CO}_{2}\right)$ conditions respectively. These are randomly selected storms from the history of the many storms that were simulated from four different experiments.

A storm from the double $\mathrm{CO}_{2}$ scenario is identified by the letter D in Fig. 6a. This storm formed east of Cuba in a monsoon trough, which extended eastward from the eastern Pacific Ocean. This storm acquired a robust intensity of $35 \mathrm{~ms}^{-1}$ on day 8 after its formation; thereafter it took a northeastward course and had a lifetime of around 11 days. It formed at around $70^{\circ} \mathrm{W}$ and $15^{\circ} \mathrm{N}$ and dissipated at around $60^{\circ} \mathrm{W}$ and $50^{\circ} \mathrm{N}$. Although the integrations were carried out at a spectral resolution of $\mathrm{T} 42$, it still contained many of the features of an asymmetric hurricane. It had a warm core with the air temperature roughly $4 \mathrm{~K}$ warmer than that of the storm's environment at $300 \mathrm{hPa}$. It had large rainfall rates in its front and right quadrants consistent with observational knowledge of north eastward moving storms. The size of the storm's cyclonic circulation, at this resolution, was roughly $1300 \mathrm{~km}$ which is evidently somewhat too large. The strongest winds, in excess of $20 \mathrm{~ms}^{-1}$, were confined to the inner $1000 \mathrm{~km}$ of the storms circulation. The region of formation of this storm had sea surface temperatures (over the eastern Caribbean Sea) of approximately $302 \mathrm{~K}\left(29^{\circ} \mathrm{C}\right)$. Other factors such as an incipient cyclonic disturbance in the lower troposphere was evident in the simulation some 2 days prior to the formation of storm D, Fig. 6a. The tropospheric humidity also met the observational criteria, i.e., the eastern side of the monsoon trough, where this storm formed, was quite humid through the middle troposphere. Fig. $6 \mathrm{~b}$ illustrates a sample storm from the current $\mathrm{CO}_{2}$ conditions. Here storm A met the conditions of a threshold storm, whereas storm B did not. Storm A lasted for a week. It formed in the southern Caribbean, acquired a maximum intensity of $28 \mathrm{~ms}^{-1}$, moved northwards, and weakened east of Florida. 
1980850 MB Observed Meon Flows

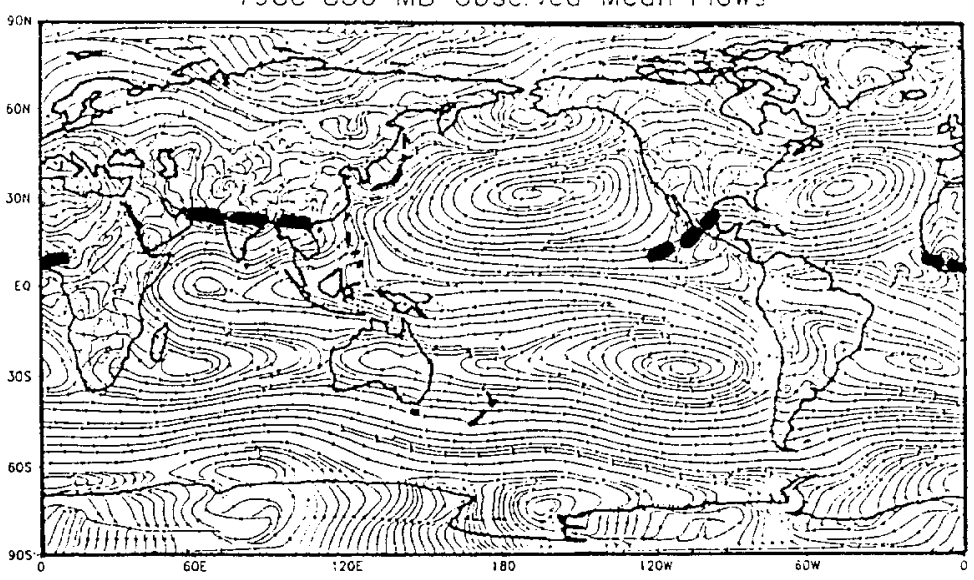

$1988850 \mathrm{MB}$ Control Mean Flows
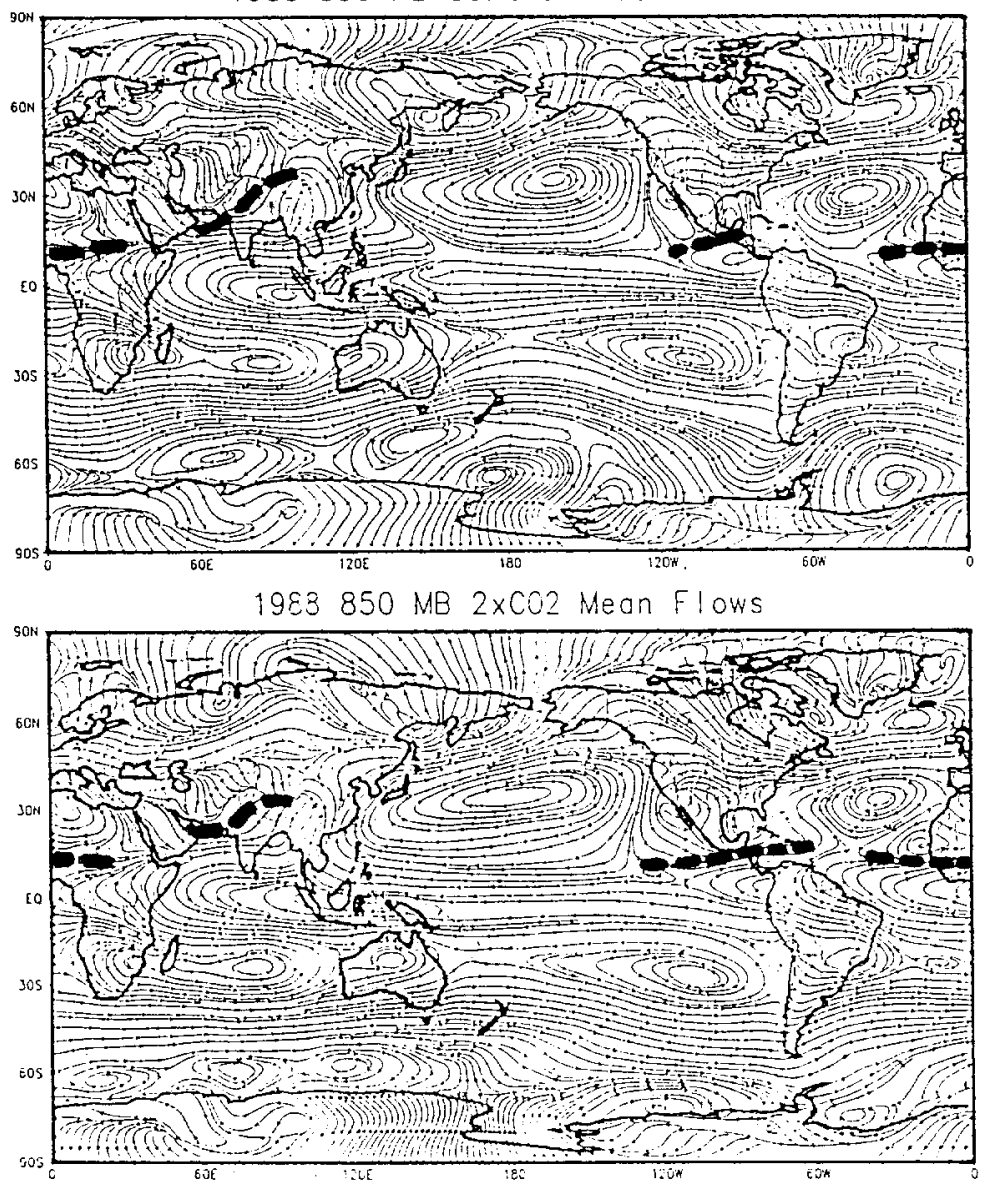

C

Fig. 5. Hurricane season mean flow field of $850 \mathrm{hPa}$, average from 1 June through 31 October. (a) Based on mean data sets for 1988 (La Niña year). (b) Results for single $\mathrm{CO}_{2}$ experiment. (c) Results for double $\mathrm{CO}_{2}$ experiment. 
Overall, the global model at the resolution of T42 appears to simulate a reasonable frequency of storms. Thus providing the possibility for generating a storm data base that could be used for investigations of storm statistics.

\subsection{Storm tracks and storm intensity}

The observed hurricane tracks for the El Niño year 1987 and the La Niña year 1988 are shown in Fig. 7a,b. There were three storms during 1987. These storms respectively originated from North of Cuba, Central Atlantic and the Caribbean. The last of these, Floyd (identified by the number 3) was a short-lived storm that formed on October 9th and lasted for 4 days. The other two storms were long lasting and had a northeasterly track.

During the La Niña year, 1988, there were 5 storms of which 4 were active over the Caribbean and the Gulf of Mexico. One of the hurricanes of this year, Helene (during September 19 to 30), formed and move northwards over the central Atlantic Ocean. The seasonal simulation of the hurricane tracks for the current $\mathrm{CO}_{2}$ conditions are shown in Fig. 8. Here we note four storms during the El Niño year, 1987, and 6 storms during the La Niña year 1988. The observed and the simulated counts for both of these experiments are within one storm of the observed seasonal totals. As for the observed, most of the storms form in the Caribbean and the Gulf of Mexico. Overall this appears to be a reasonable simulation in terms of frequency and general location of tracks. The modeling experience of several groups, Haarsma et al. (1993), Tsutsui and Kashahara (1996), has shown a tendency for storm activity to be biased towards the western Atlantic, Caribbean and the Gulf of Mexico. Without further experimentation it would be difficult to state whether the FSU model has such a bias. Our studies with real data, briefly reviewed in Section 2, did not appear to suggest that.

When we double the $\mathrm{CO}_{2}$ and spin up the model for 6 months and then carry out a seasonal simulation we start to see some major differences in the number of storms, Fig. 9. For the El Niño years of the single and the double $\mathrm{CO}_{2}$ experiments the number of hurricanes over the Atlantic were nearly the same. However, the picture changed drastically for the La Niña year. Here we see almost double the number of storms for the double $\mathrm{CO}_{2}$ simulations as compared to those for the single $\mathrm{CO}_{2}$.

There were several factors in the simulation of the double $\mathrm{CO}_{2}$ La Niña year that may have contributed to the increased frequency of hurricanes. The most obvious one is the warmer sea surface temperature anomalies that were imposed over the Atlantic. That enhancement of SSTA over the Atlantic compared to that of the La Niña year, 1988, was of the order of 1.5 K. Furthermore, other factors such as diminished tropospheric wind shear, stronger cyclonic vorticity in the lower troposphere and an enhancement of middle tropospheric moisture appeared to be significant. It is difficult to state whether the changes in the frequency of storms, noted here, arise simply from the enhanced $\mathrm{CO}_{2}$ or the enhanced SST anomalies. However it is our contention that the storm formation is a very strong function of the SST distributions. Future studies are needed to sort out the impacts of these two separate enhancements. Some differences could be attributed simply to the use of different start dates, i.e. an initial state sensitivity. However we feel that these large differences in the number of simulated storms are largely influenced by the prescribed SST. Ensemble forecasts using different start dates may be needed to provide a convincing answer to this question.

The tracks of the triple $\mathrm{CO}_{2}$ storms are indicated in Fig. 10. This only includes that portion of the tracks where the maximum winds met our definition of a hurricane. All of the storms met this criteria over the Gulf of Mexico, Caribbean Sea and the Western Atlantic Ocean. Although these hurricanes originated as tropical waves farther east of the indicated initial positions, most of the intensification occurred in the western part of this domain.

Table 1 summarizes the results, from all experiments, on the intensity issue. Column 1 identifies the storms. The column 1987s includes the maximum intensity for the El Niño year storms for the single $\mathrm{CO}_{2}$. The other columns 1987d, 1988s, $1988 \mathrm{~d}$ and $3 \times \mathrm{CO}_{2}$ respectively, include the results on the maximum intensity for the El Niño year storms with double $\mathrm{CO}_{2}$; the La Niña year with double $\mathrm{CO}_{2}$; the La Niña year with double $\mathrm{CO}_{2}$; and the results for a triple $\mathrm{CO}_{2}$ experiment.

We find that for the seasonal average: (a) there are fewer storms during El Niño years compared 


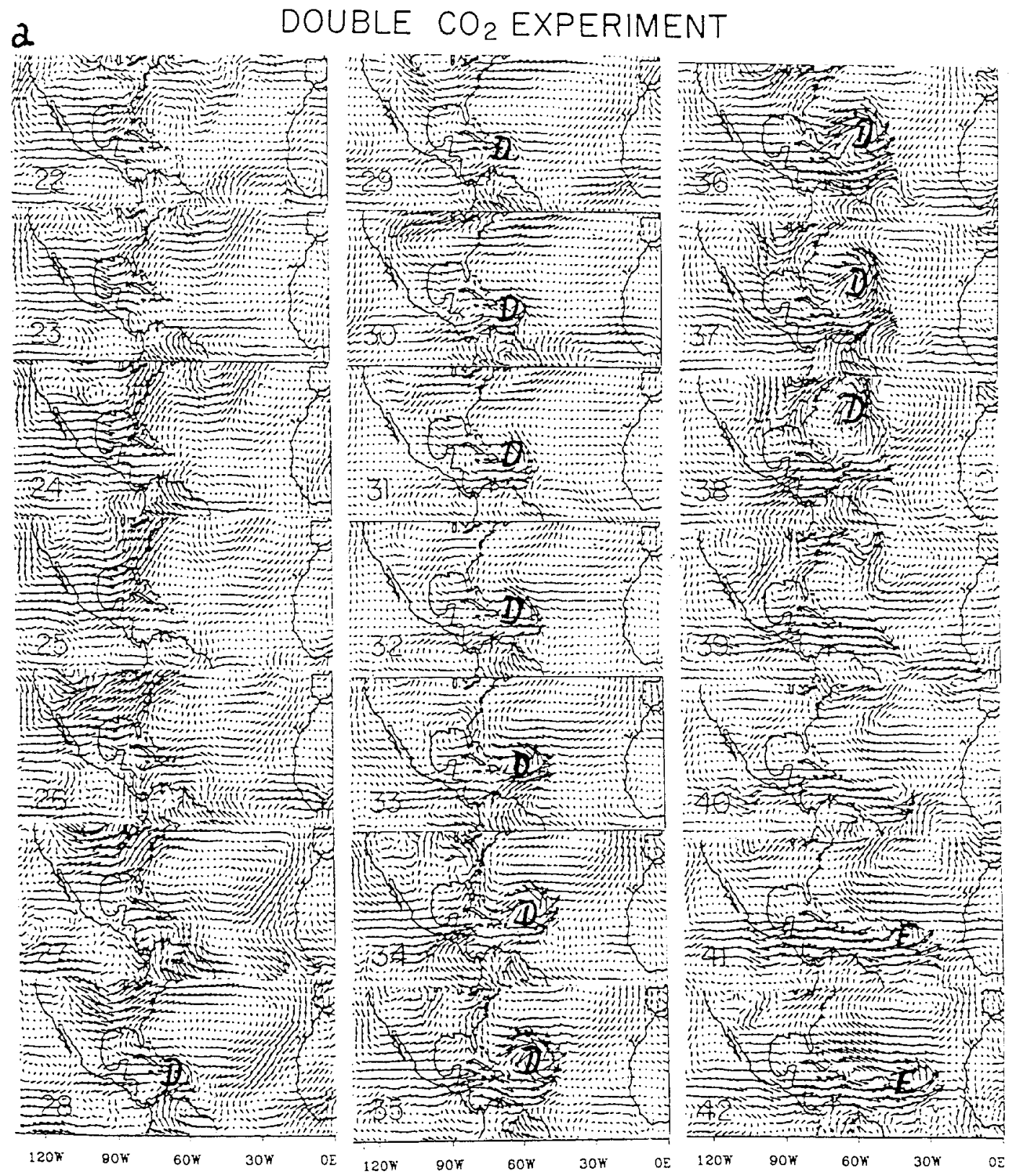

Fig. 6. A sequence of daily vector flow charts at $850 \mathrm{hPa}$ for (a) a double $\mathrm{CO}_{2}$ experiment and (b) a single $\mathrm{CO}_{2}$ experiment. Individual storms are identified by letters. The vector length scale is given at the bottom right of the illustration. 


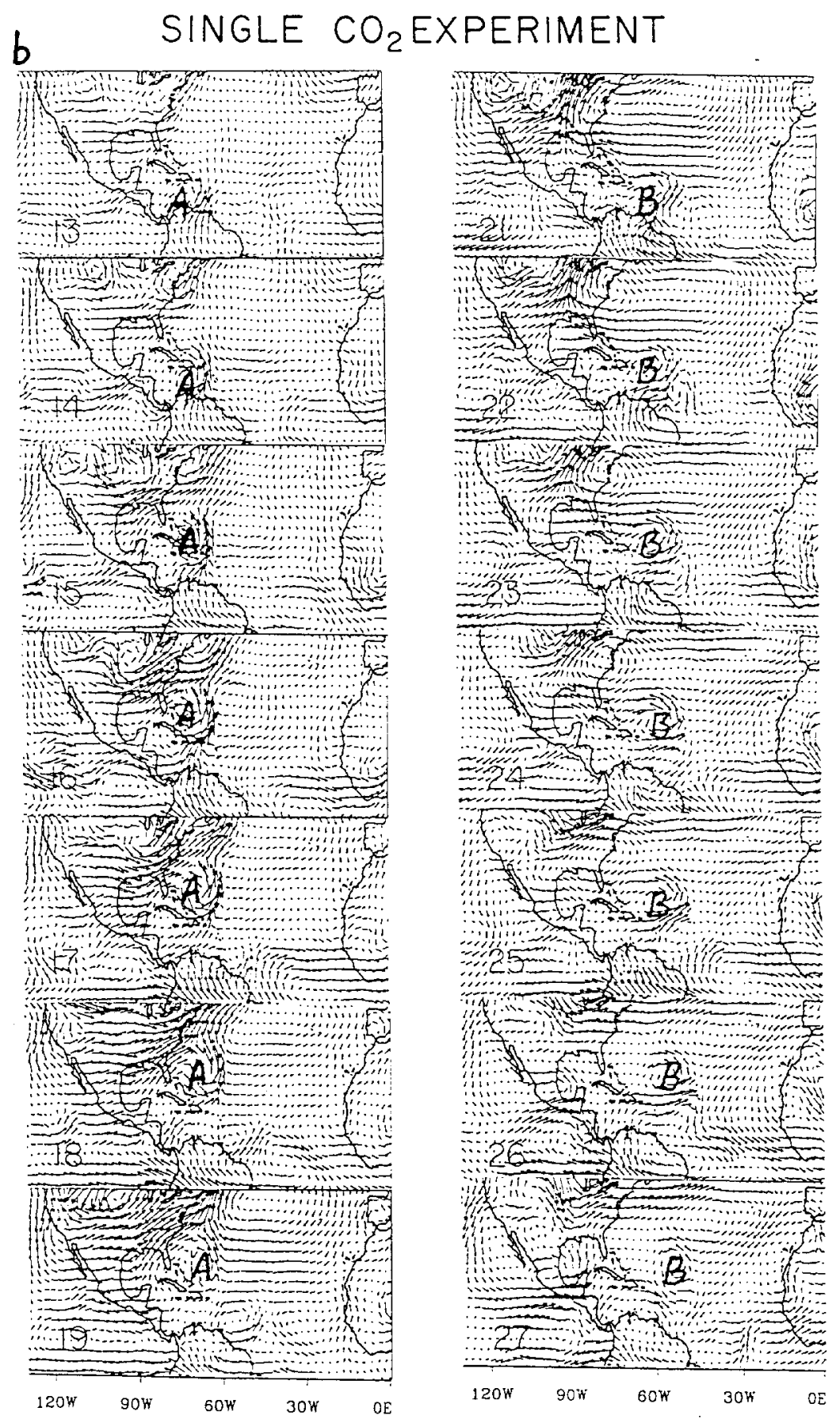

Fig. 6 (cont'd). 


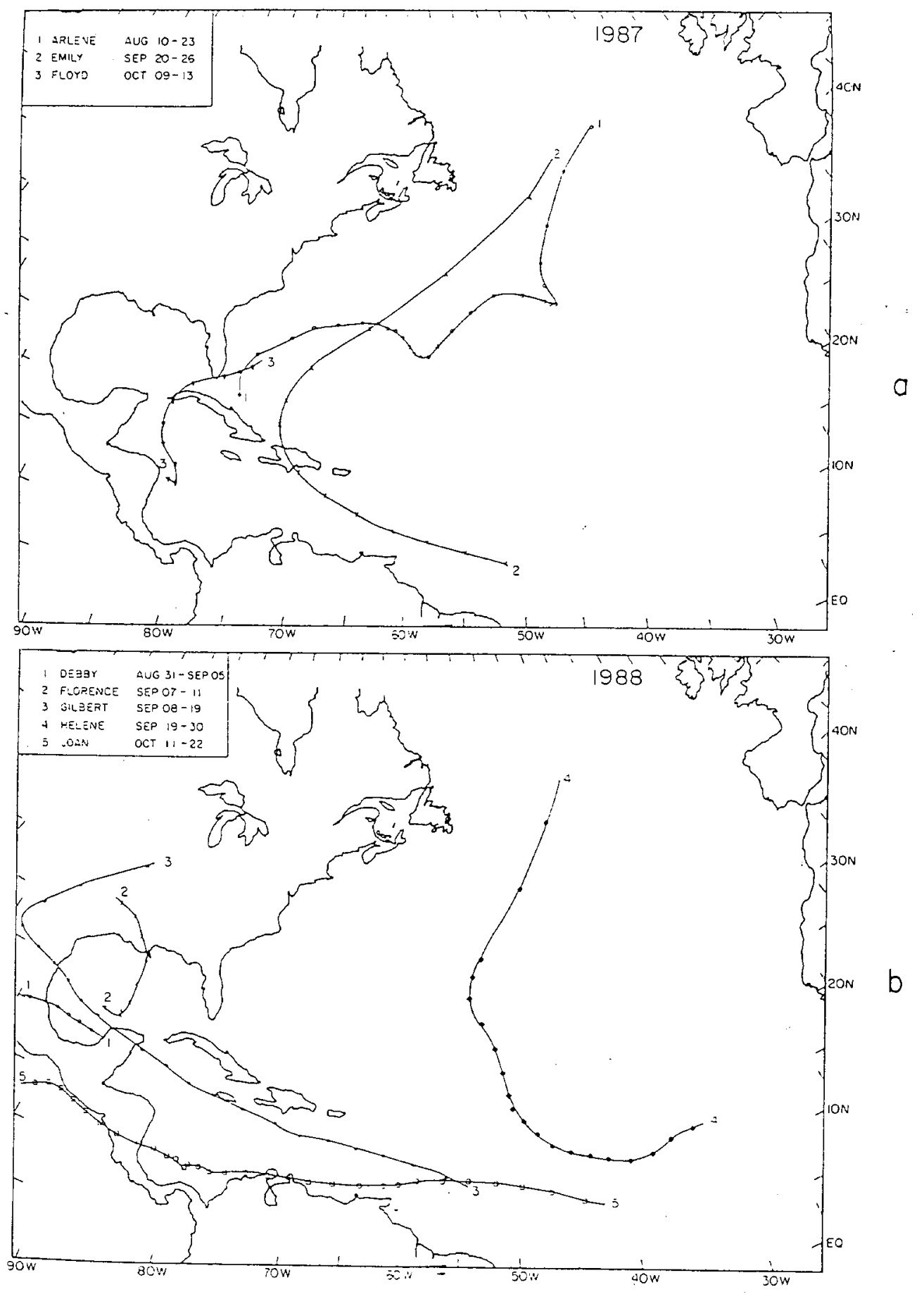

Fig. 7. Observed storm tracks for an El Niño and a La Niña year, i.e., for the years (a) 1987 and (b) 1988. 
1987 CONTROL EXPERIMENT STORM TRACKS
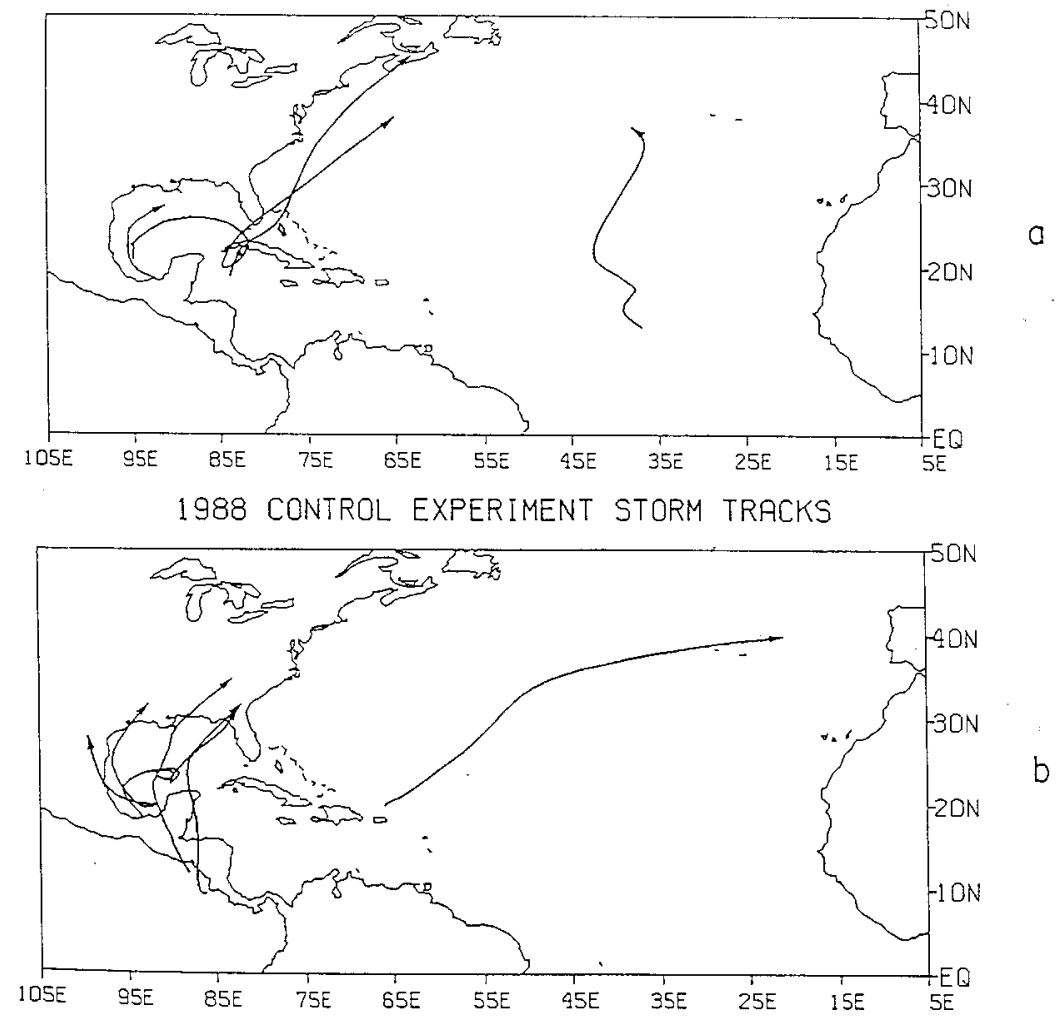

Fig. 8. Seasonal prediction of storm tracks for the current $\mathrm{CO}_{2}$ conditions: (a) El Niño year; (b) La Niña year.

to the La Niña years for the single and the double $\mathrm{CO}_{2}$ experiments; (b) the number of storms for the double $\mathrm{CO}_{2} \mathrm{La}$ Niña year were nearly double those for the single $\mathrm{CO}_{2}$ La Niña year; (c) the maximum intensity (measured by the maximum wind at $850 \mathrm{hPa}$ for a storm) is larger for the double $\mathrm{CO}_{2}$ storms compared to the single $\mathrm{CO}_{2}$ storms; (d) the strongest storms were noted for a triple $\mathrm{CO}_{2}$ experiment when the average intensity was as high as $38 \mathrm{~ms}^{-1}$. Some of the storms reached an intensity as high as $45 \mathrm{~ms}^{-1}$.

In summary, the number of storms under global warming increased in number during the La Niña years and were somewhat more intense compared to those of the current climate simulations. The triple $\mathrm{CO}_{2}$ experiment using the SST anomaly distribution provided by the Max Planck Institut showed some of the most intense storms.

\subsection{Precipitation in different experiments}

This includes the overall global distribution of precipitation from the various experiments. Fig. 11 illustrates the mean daily hurricane seasonal rainfall for the following four experiments: El Niño (single $\mathrm{CO}_{2}$ ), El Niño (double $\mathrm{CO}_{2}$ ), La Niña (single $\mathrm{CO}_{2}$ ) and La Niña (double $\mathrm{CO}_{2}$ ). At this stage, we shall simply compare these panels with respect to each other.

- Over West Africa and the eastern and the western Atlantic oceans, the heaviest rainfall was noted for the double $\mathrm{CO}_{2}$ experiment of the $\mathrm{La}$ Niña year; this was more than the mean rainfall among all experiments.

- Monsoon rainfall was also larger between $60^{\circ} \mathrm{E}$ and $150^{\circ} \mathrm{E}$ for the double $\mathrm{CO}_{2}$ experiment of the La Niña year.

- Bay of Bengal and Burmese rainfall amounts 
1987 DOUBLE CO2 EXPERIMENT STORM TRACKS
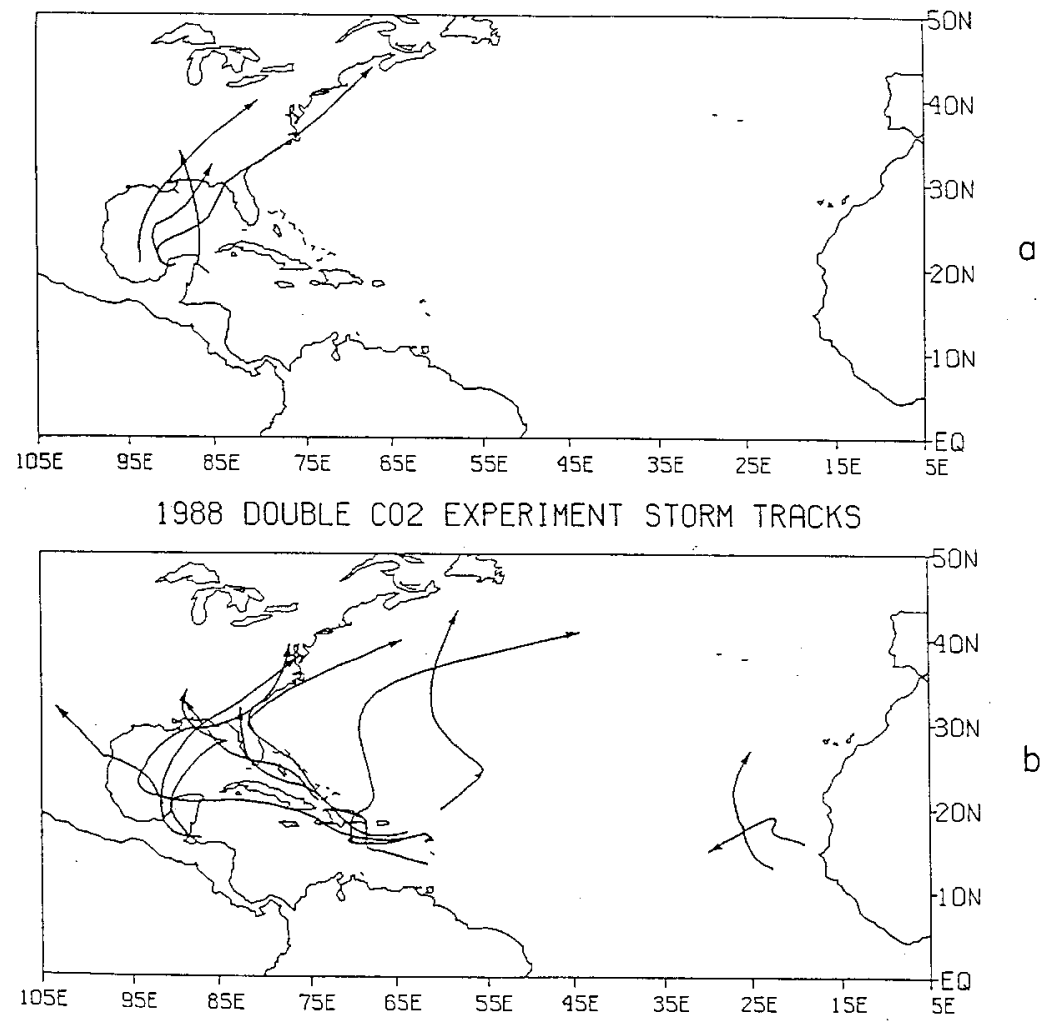

Fig. 9. Seasonal prediction of storm tracks for the double $\mathrm{CO}_{2}$ conditions: (a) El Niño year; (b) La Niña year.

TRIPLE CO2 EXPERIMENT STORM TRACKS

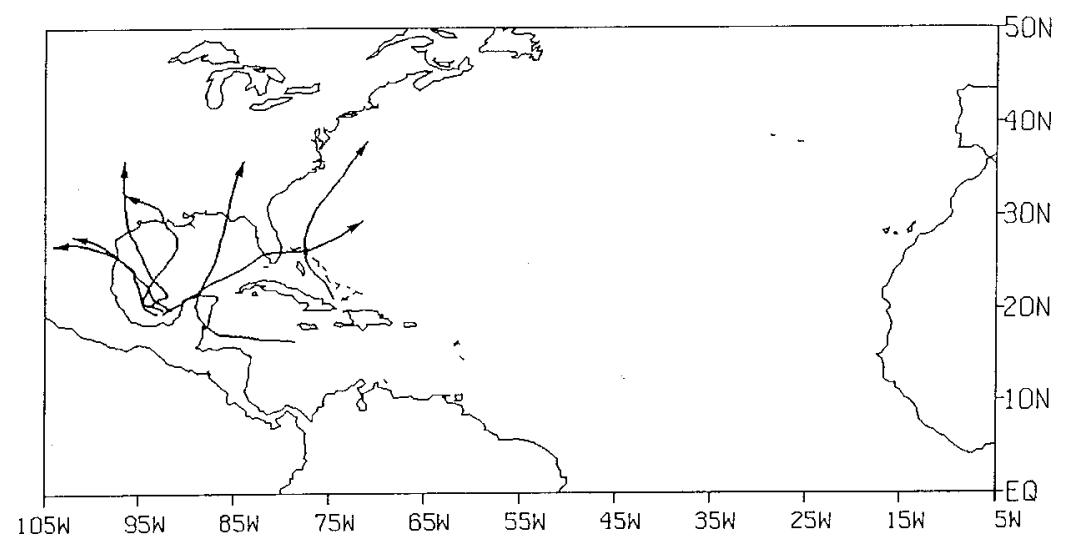

Fig. 10. Storm tracks for the triple $\mathrm{CO}_{2}$ experiment. 
Table 1. Maximum intensity of individual hurricanes in each of the 5 simulations, 1 June31 October; units are in $\mathrm{ms}^{-1}$.

\begin{tabular}{cccccc}
\hline No. & $1987 \mathrm{~s}$ & $1987 \mathrm{~d}$ & $1988 \mathrm{~s}$ & $1988 \mathrm{~d}$ & $3 \times \mathrm{CO}_{2}$ \\
\hline 1 & 25 & 33 & 18 & 40 & 39 \\
2 & 42 & 38 & 33 & 33 & 39 \\
3 & 29 & 34 & 25 & 39 & 36 \\
4 & 26 & 42 & 48 & 28 & 38 \\
5 & & & 31 & 32 & 39 \\
6 & & & 33 & 28 & 45 \\
7 & & & & 29 & 34 \\
8 & & & & 41 & \\
9 & & & & 25 & \\
10 & & & & 40 & \\
11 & & & & 25 & \\
mean & 30.5 & 36.8 & 31.3 & 32.7 & 38.6 \\
\hline
\end{tabular}

$\mathrm{s}=$ control forecast $\mathrm{d}=$ double $\mathrm{CO}_{2}$ forecast; $3 \times \mathrm{CO}_{2}=$ triple $\mathrm{CO}_{2}$ experiment.

were excessive for the La Niña year of the current climate simulations.

- Both global warming experiments exhibited heavier rain over the equatorial latitudes of the monsoon between $90^{\circ} \mathrm{E}$ and the date line.

- Equatorial African rainfall was largest for the global warming experiment during the El Niño year.

- Over the Central Pacific region rainfal amounts were largest for both El Niño experiments. The largest amounts, as to be expected, were for the global warming experiment for the El Niño conditions.

In the context of the hurricanes, the entire tropical Atlantic experienced excessive rains for the La Niña experiment with the enhanced $\mathrm{CO}_{2}$. This of course reflects the enhanced storm activity.

In the triple $\mathrm{CO}_{2}$ experiment, Fig. 12, excessive rainfall was noted over the Northern Bay of Bengal and Venezuela. If we compare the triple $\mathrm{CO}_{2}$ rain with those from the other four experiments, we find that the Western Atlantic, Gulf of Mexico, the Caribbean and the Southeast and the Central US experience more rain. This is clearly evident from the spread of the $5 \mathrm{~mm}$ /day isopleth. This excess of rain came from the slightly stronger storms that were noted in this experiment.

\section{Beyond the range of conventional predictability}

The formation of hurricanes has been attributed to a number of factors (Gray, 1968) such as warm
SST's (greater than roughly $299 \mathrm{~K}$ or $26^{\circ} \mathrm{C}$ ), weak vertical shear of the horizontal wind, the presence of a pre-existing cyclonic disturbance (such as an easterly wave or a low pressure trough), and the presence of excess moisture in the lower to middle troposphere. Errors in predictability of tropical motions beyond roughly 6 days can contribute to large errors in the location of the region of weak vertical shear, incipient (pre-hurricane) disturbances, and the vertical distribution of moisture. The prescribed SST anomalies alone do not guarantee that the seasonal simulation beyond this conventional range of predictability would define the proper statistical locations for the formation of hurricanes. The time history of the evolution of vertical shears, lower tropospheric cyclonic vorticity and the tropospheric humidity are rather complex in a climate model. Here we shall illustrate the time history of these variables as seen by the model and as seen from the analysis of real data for the hurricane season of 1988.

\subsection{Evolution of zonal wind shear}

A comparison of the tropospheric shear of the zonal wind over the latitudes where hurricanes form for the single and the double $\mathrm{CO}_{2}$ experiments is of considerable interest. In this context, we shall examine the simulated data sets for the La Niña SST configurations. Noting that we had more storms for the double $\mathrm{CO}_{2}$ compared to the single $\mathrm{CO}_{2}$, we perhaps should expect a weaker vertical shear of the horizontal wind over the Atlantic Ocean for the double $\mathrm{CO}_{2}$ experiment. Here we shall show the vertical shear $200 \mathrm{hPa}$ minus $850 \mathrm{hPa}$ zonal winds which are meridionally averaged between $5^{\circ} \mathrm{N}$ and $20^{\circ} \mathrm{N}$. This is illustrated in Fig. 13, via Hovmöller diagrams $(x-t$ plot). The most conspicuous change is in the region of the Indian monsoon where the vertical shears decreased. As a matter of fact, the monsoon weakened for the $2 \mathrm{CO}_{2}$ experiment. Over the Atlantic Ocean between $30^{\circ} \mathrm{W}$ and $70^{\circ} \mathrm{W}$, the vertical shear was, for a considerable length of time, in fact lower near $60^{\circ} \mathrm{W}$ for the double $\mathrm{CO}_{2}$ experiment compared to the single $\mathrm{CO}_{2}$ experiment. This shear also exhibits some degree of intermittence. Around the 14 July, 18 September, and 16 October, large shears developed for the double $\mathrm{CO}_{2}$ experiment, but they did not last for more than a few days. The 11 storms that formed 
T. N. KRISHNAMURTI ET AL.
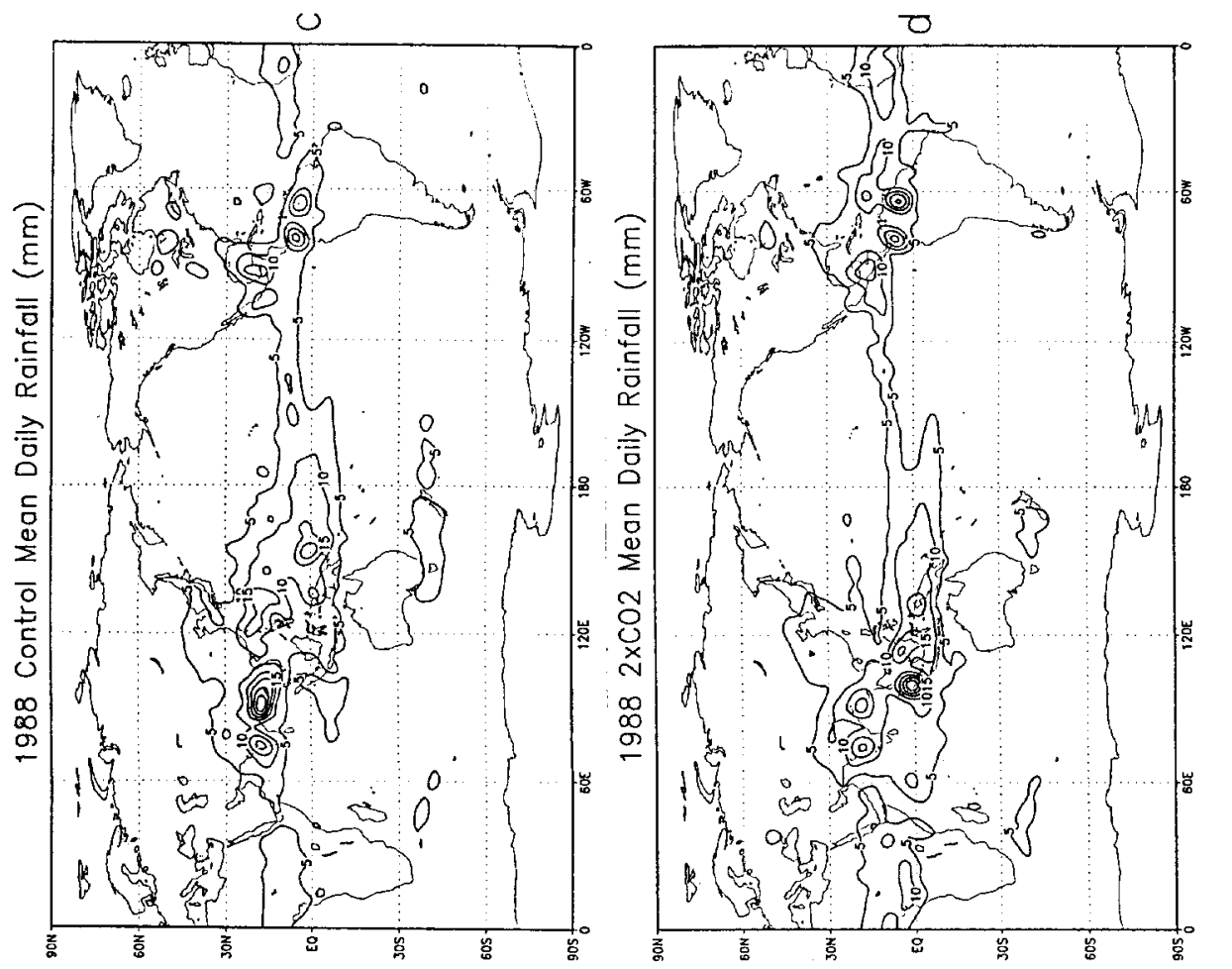

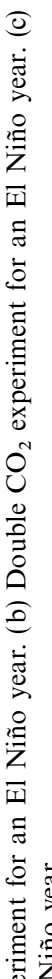
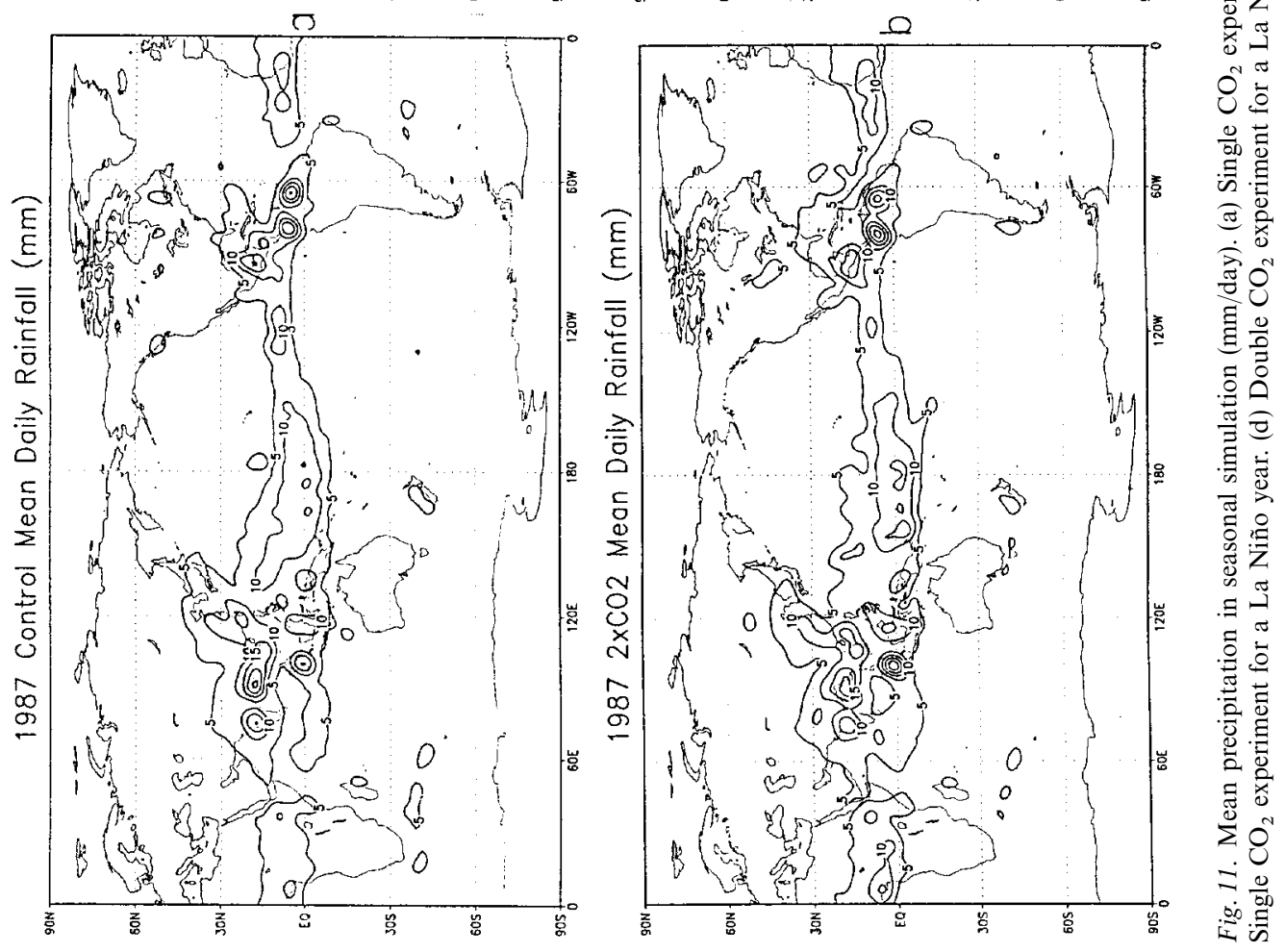

Tellus 50A (1998), 2 
Triple CO2 Case Mean Daily Rainfall $(\mathrm{mm})$

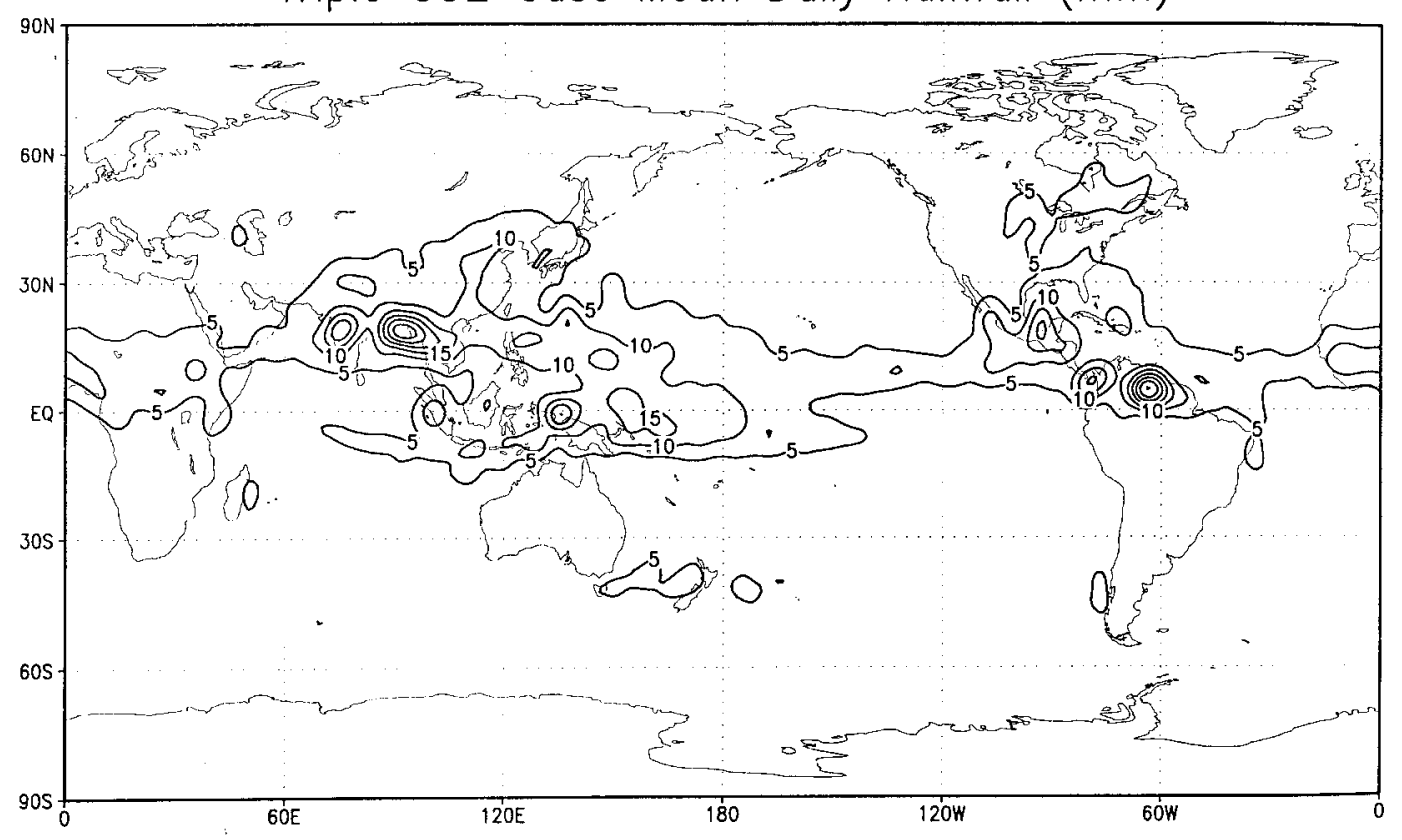

Fig. 12. Seasonal mean precipitation for the triple $\mathrm{CO}_{2}$ experiment, units $\mathrm{mm} /$ day.

for the double $\mathrm{CO}_{2}$ and the 5 storms that formed for the single $\mathrm{CO}_{2}$ experiment all formed during the periods of weak vertical shear of the zonal wind. These shears were of the order of $5 \mathrm{~ms}^{-1}$.

\subsection{Humidity over the middle troposphere}

A middle tropospheric enhancement of humidity has been noted preceding the formation of hurricanes. A substantial enhancement of this middle tropospheric relative humidity was noted for the double $\mathrm{CO}_{2}$ experiment. A Hovmöller diagram of the $500 \mathrm{hPa}$ relative humidity (meridionally averaged between $5^{\circ} \mathrm{N}$ and $20^{\circ} \mathrm{N}$ ) is shown in Fig. 14a,b. A comparison of the single and the double $\mathrm{CO}_{2}$ experiment shows that during the period between mid-July to mid-August, higher relative humidities prevailed for the double $\mathrm{CO}_{2}$ experiment over the western Atlantic Ocean west of $60^{\circ} \mathrm{W}$. These locations of higher humidities were consistent with the larger storm frequency over the western Atlantic and the Gulf of Mexico. The most humid region of the Asian monsoon, located near $130^{\circ} \mathrm{E}$ (single $\mathrm{CO}_{2}$ ), moves westward towards $110^{\circ} \mathrm{E}$ for the double $\mathrm{CO}_{2}$ experiment.
The monsoon behavior will be discussed in a separate paper.

\subsection{Lower tropospheric relative vorticity and meridional winds}

Hovmöller diagrams, at the $850 \mathrm{hPa}$ level, for the relative vorticity (meridionally averaged between $5^{\circ} \mathrm{N}$ and $20^{\circ} \mathrm{N}$ ) are shown in Fig. 15 . These are the respective diagrams for the single and the double $\mathrm{CO}_{2}$ experiments. The presence of a lower tropospheric cyclonic vorticity maximum is considered as another requirement for the formation of hurricanes and typhoons. In Fig. 15a, i.e., for the single $\mathrm{CO}_{2}$ experiment, we can clearly see a number of westward propagating equatorial waves (or easterly waves) from the central to the western Pacific Ocean. There is also such wave activity in the Atlantic Ocean between the Greenwich meridian and $45^{\circ} \mathrm{W}$, although the degree of activity over the Atlantic appears to be much less than that over the Pacific Ocean. A belt of quasi-stationary vortices exists near $90^{\circ} \mathrm{W}$ and near $90^{\circ} \mathrm{E}$ longitudes. Both of these denote orographic vortices over central America and over the Burmese highlands. The most conspicuous 

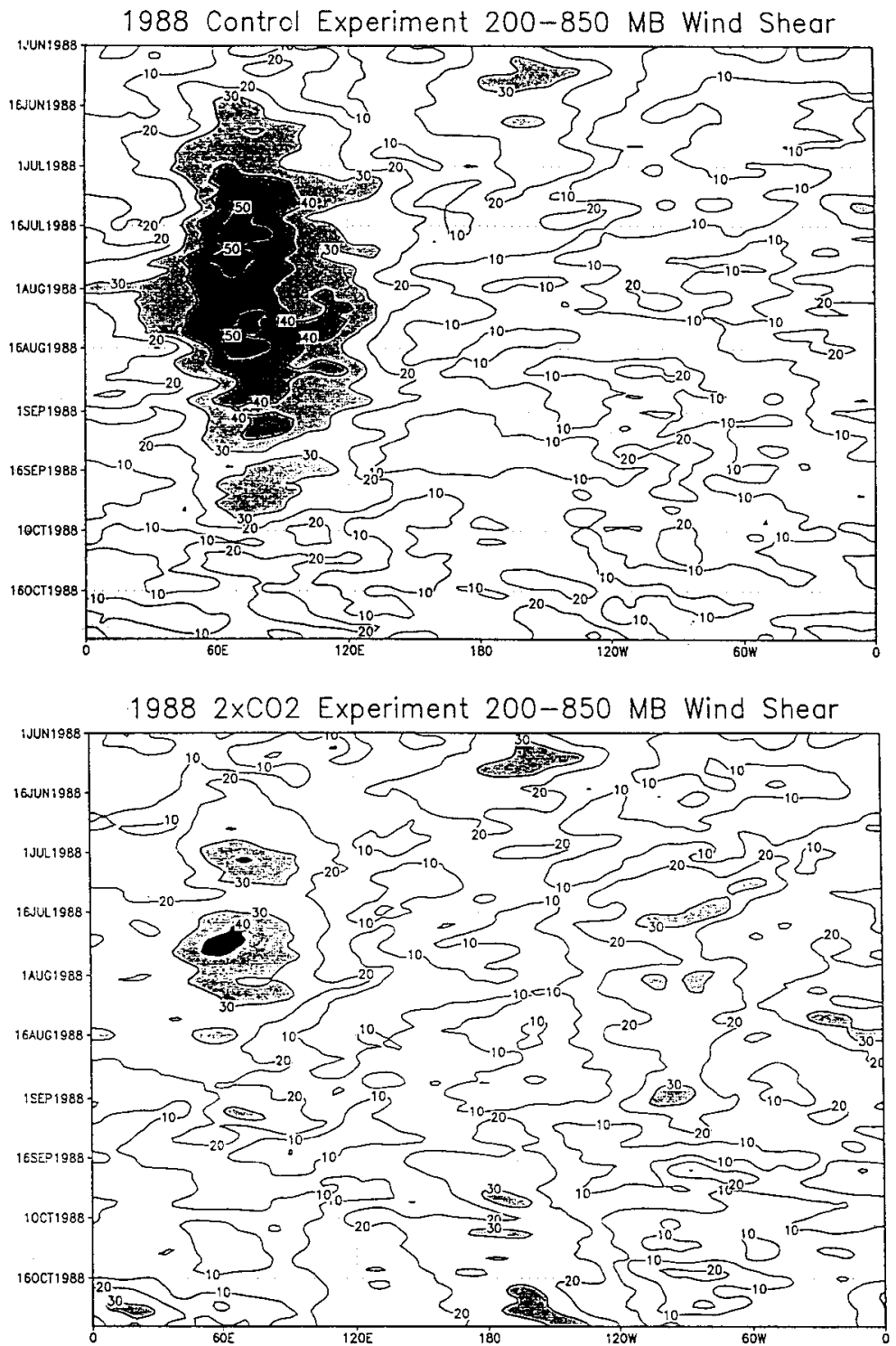

Fig. 13. A $x-t$ diagram of the shear of the zonal wind ( $200 \mathrm{hPa}$ zonal wind minus $850 \mathrm{hPa}$ zonal wind) meridionally averaged from $5^{\circ} \mathrm{N}$ to $20^{\circ} \mathrm{N}$, units $\mathrm{ms}^{-1}$ : (a) single $\mathrm{CO}_{2}$ simulations for a La Niña year; (b) double $\mathrm{CO}_{2}$ simulations for a La Niña year.

difference in the double $\mathrm{CO}_{2}$ experiment (Fig. 15b) is the less pronounced wave activity over the central Pacific Ocean. Wave activity is pronounced between $50^{\circ} \mathrm{E}$ and $120^{\circ} \mathrm{E}$, the stationary belt of vortices neat $90^{\circ} \mathrm{E}$ is weaker, and the one near $90^{\circ} \mathrm{W}$ is stronger, especially in the months of September and October. Tropical Atlantic is cle- arly more active for this double $\mathrm{CO}_{2}$, Fig. 15b, experiment compared to the single $\mathrm{CO}_{2}$ experiment, Fig. 15a.

The aforementioned disturbance activity can also be monitored from a Hovmöller diagram of the meridional wind component. That diagram for the $850 \mathrm{hPa}$ model output history is shown in 

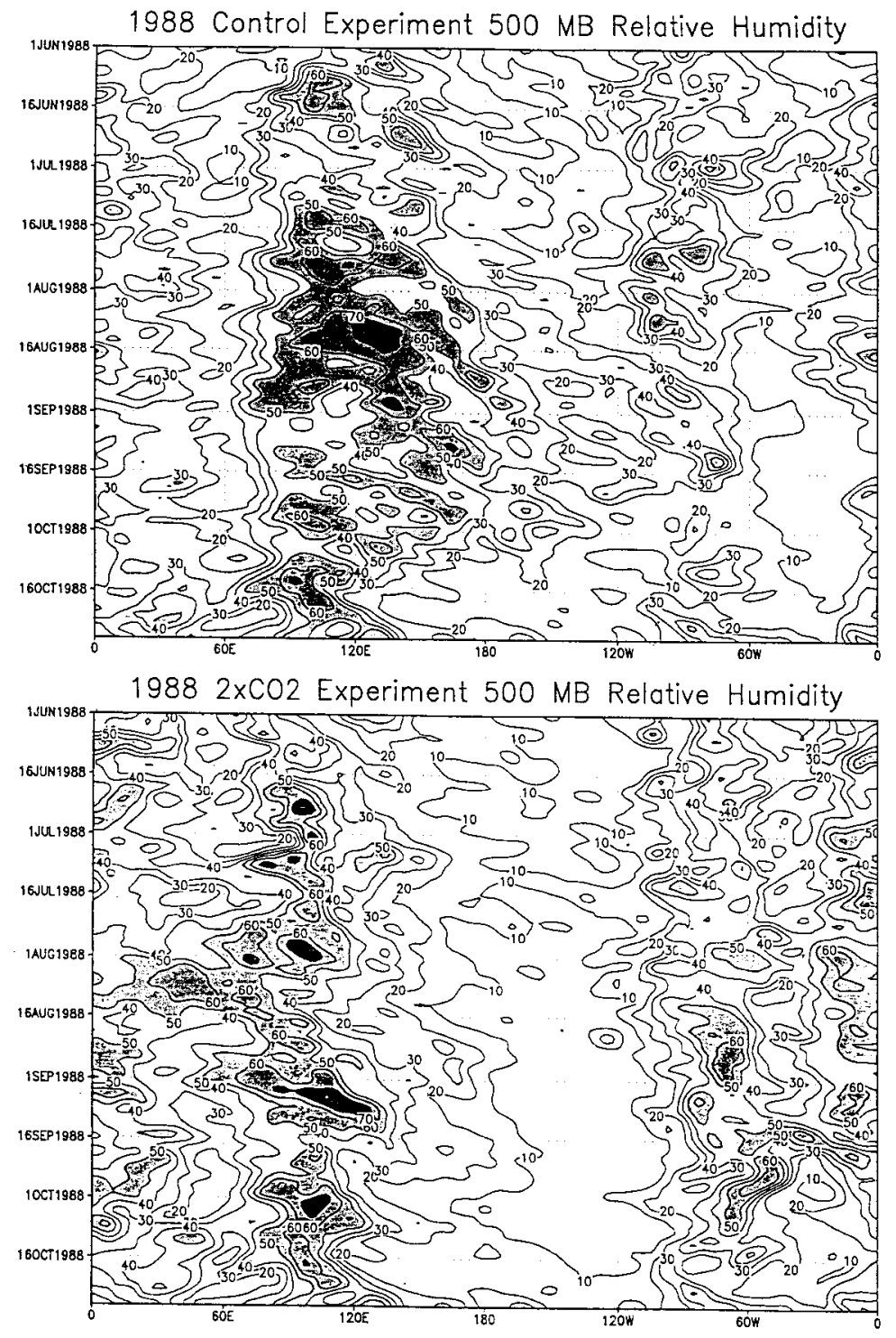

Fig. 14. An $x-t$ diagram of the $500 \mathrm{hPa}$ relative humidity, meridionally averaged from $5^{\circ} \mathrm{N}$ to $20^{\circ} \mathrm{N}$ : (a) single $\mathrm{CO}_{2}$ simulations for a La Niña year; (b) double $\mathrm{CO}_{2}$ simulations for a La Niña year.

Fig. 16a,b. These respectively show the results for the single and the double $\mathrm{CO}_{2}$ experiments. The meridional wind in these Hovmöller diagrams are meridionally averaged over the latitude belt between $5^{\circ} \mathrm{N}$ and $20^{\circ} \mathrm{N}$. Here we confirm the same results that we note from the distribution of relative vorticity. The double $\mathrm{CO}_{2}$ results show stronger wave activity over the Atlantic and somewhat weaker activity over the Pacific Ocean. The activity over the Indian Ocean appears to be about the same for both the double and single $\mathrm{CO}_{2}$ experiments. The magnitude of this (meridionally averaged) meridional wind lies, roughly, between -6 and $+7 \mathrm{~ms}^{-1}$.

Tellus 50A (1998), 2 

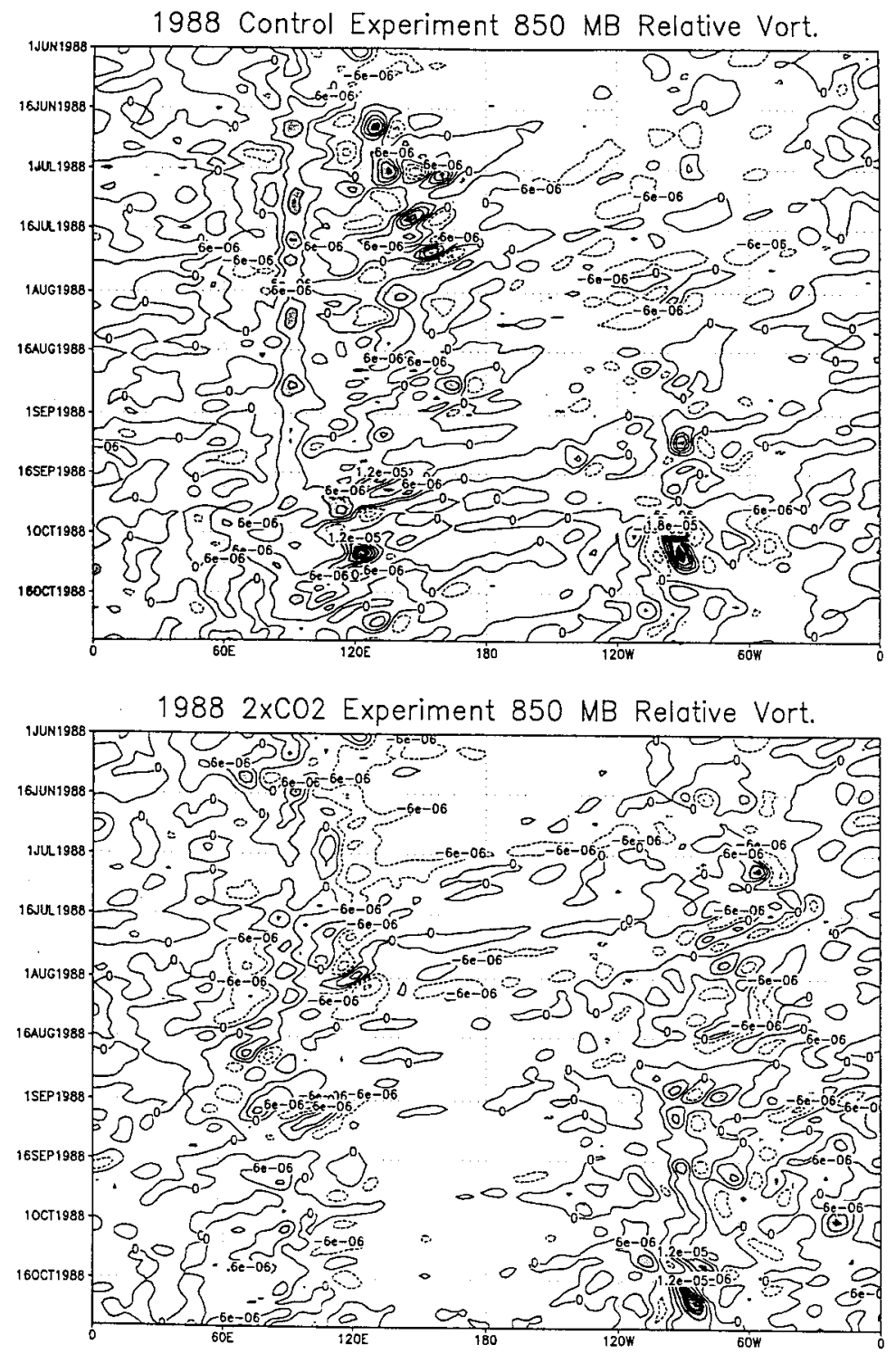

Fig. 15. An $x-t$ diagram of the $850 \mathrm{hPa}$ relative vorticity, meridionally averaged from $5^{\circ} \mathrm{N}$ to $20^{\circ} \mathrm{N}$, units s s $^{-1}$. (a) single $\mathrm{CO}_{2}$ simulations for a $\mathrm{La}$ Niña year; (b) double $\mathrm{CO}_{2}$ simulations for a $\mathrm{La}$ Niña year.

\section{Concluding remarks}

The results of this study are as follows.

(i) When we carry out season long integrations of our atmospheric model, we find that the number of hurricanes we have simulated for the current day $\mathrm{CO}_{2}$ conditions are somewhat less for the $\mathrm{El}$
Niño year as compared to those for a La Niña year.

(ii) Under the assumption that El Niños and La Niñas shall continue to occur under the enhanced $\mathrm{CO}_{2}$ conditions, we have constructed modeled SST anomalies assuming a $0.5 \mathrm{~K}$ net global tropical oceanic warming. The number of 
1988 Control Experiment $850 \mathrm{MB} \vee$ Wind Comp.
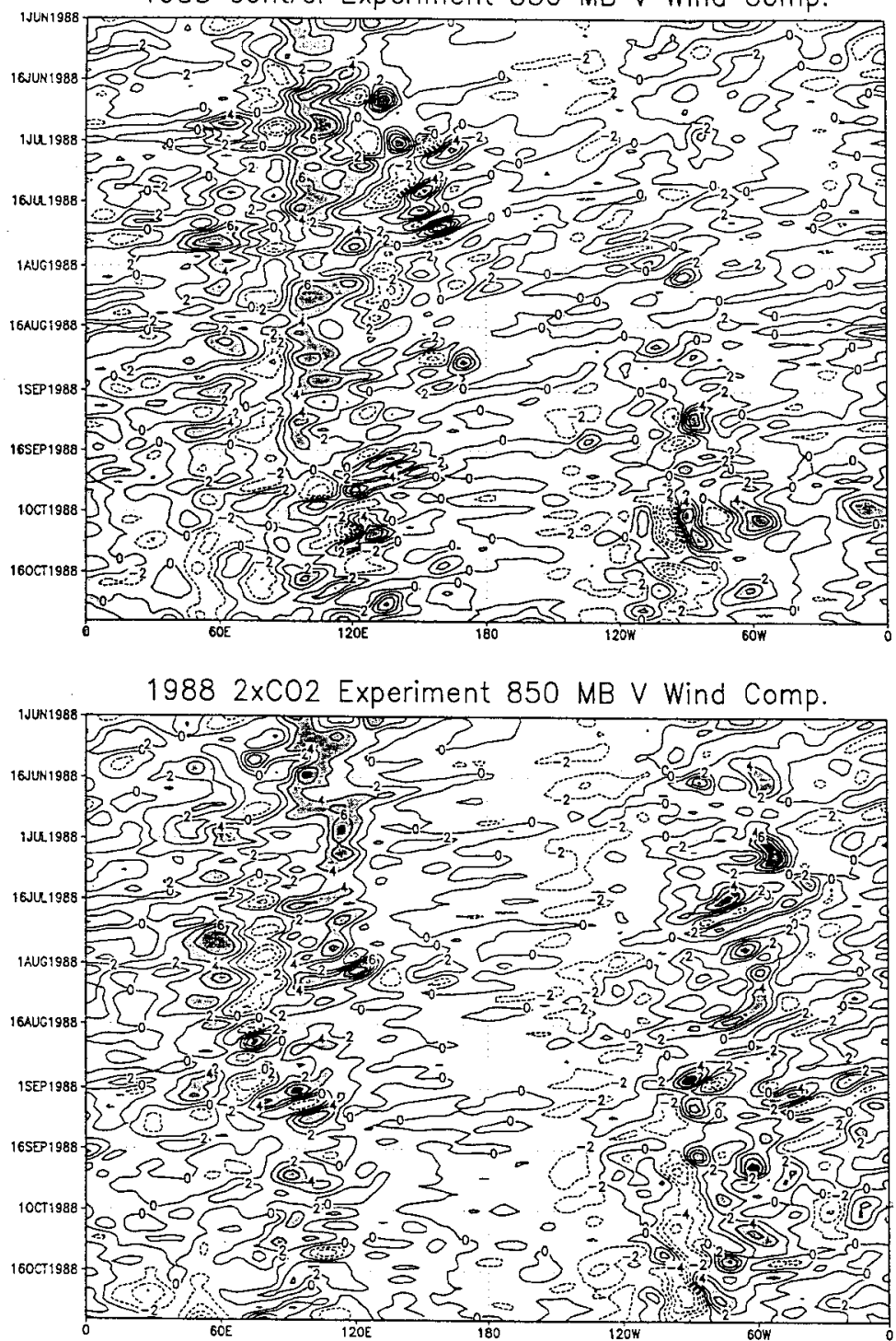

Fig. 16. An $x$ - $t$ diagram of the meridional wind at $850 \mathrm{hPa}$, meridionally averaged from $5^{\circ} \mathrm{N}$ to $20^{\circ} \mathrm{N}$, units $\mathrm{ms}^{-1}$ : (a) single $\mathrm{CO}_{2}$ experiment for a La Niña year and (b) double $\mathrm{CO}_{2}$ experiment for a $\mathrm{La}$ Niña year.

hurricanes were nearly the same for the single and the double $\mathrm{CO}_{2}$ experiments of the El Niño. However, we see a doubling in the number of hurricanes when the La Niña configured SST anomalies are used for the doubled $\mathrm{CO}_{2}$.

(iii) We extracted the SST anomaly fields from a triple $\mathrm{CO}_{2}$ coupled ocean-atmospheric model run of the Max Planck Institut of Hamburg. Using these SST anomalies, we carried out a hurricane season long integration with the FSU atmospheric global model. The results showed a slight enhancement in the number and an intensification of

Tellus 50A (1998), 2 
Atlantic hurricanes compared to the El Niño experiments.

The issue of hurricane frequency and intensity for the global warming scenarios needs to be addressed under a controlled model intercomparison initiative. A thrust similar to that of Atmospheric Model Intercomparison Project (AMIP) may be necessary to identify the similarities and dissimilarities in the hurricane modeling efforts. To obtain a consensus in such modeling results might perhaps take a decade of model intercomparison exercises. Such a model intercomparison is not intended to identify a single "best" model or provide common features; hopefully a detailed intercomparison may be revealing on the deficiencies of the models in some areas.

A host of modeling differences such as resolution, physical parameterization, discretization of model grids can all contribute to differences in the climate simulations. Perhaps the only standardization that has occurred in the last two decades is the widespread use of spectral transform methods by most users. That has lead to the use of nearly identical algorithms for the evaluation of advective nonlinearities in global spectral models. Such is not the case for most other areas of these models.

As discussed by Cess et al. (1993), the radiative forcing in many general circulation models responds differently to change in the global surface temperature largely due to differences in parameterizing effects of clouds. Since the radiative forcing determines the characteristics of atmospheric circulation systems, further work is clearly needed to explore the sensitivity of storm behavior for different types of patterns of SST.

The few experiments illustrated here do not qualify to provide any definitive statements on the intensity issue. We find that, in general, the global warming experiments do yield some of the stronger storms, especially those for the La Niña year and for the triple $\mathrm{CO}_{2}$ SST's which were provided to us by the Hamburg group.

The results of this study are, no doubt, quite preliminary. We are only showing the results of 5 atmospheric general circulation model results. The samples of El Niño and La Niña are too few to make any strong recommendations for global change issues. The results need to be followed up with a larger sample of experiments and better modeling. It is hoped that these preliminary experimental results may draw others to carry out a more serious experimental program.

\section{Appendix}

An outline of the FSU global spectral model

The global model used in this study is identical in all respects to that used in Krishnamurti et al. (1991). The following is an outline of the global model:

(a) independent variables: $(x, y, \sigma, t)$.

(b) dependent variables: vorticity, divergence, surface pressure, vertical velocity, temperature and humidity;

(c) horizontal resolution: triangular 42 waves;

(d) vertical resolution: 15 layers between roughly 50 and $1000 \mathrm{mb}$;

(e) semi-implicit time differencing scheme;

(f) envelope orography (Wallace et al., 1983);

(g) centered differences in the vertical for all variables except humidity which is handled by an upstream differencing scheme;

(h) fourth order horizontal diffusion (Kanamitsu et al., 1983);

(i) Kuo-type cumulus parameterization (Krishnamurti et al., 1983);

(j) shallow convection (Tiedke, 1984);

(k) dry convective adjustment;

(1) large-scale condensation (Kanamitsu, 1975);

(m) surface fluxes via similarity theory (Businger et al., 1971);

(n) vertical distribution of fluxes utilizing diffusive formulation where the exchange coefficients are functions of the Richardson number (Louis, 1979);

(o) long- and short-wave radiative fluxes based on a band model (Harshvardan and Corsetti, 1984; Lacis and Hansen, 1974);

(p) diurnal cycle;

(q) parameterization of low, middle and high clouds based on threshold relative humidity for radiative transfer calculations;

(r) surface energy balance coupled to the similarity theory (Krishnamurti et al. 1991);

(s) non-linear normal mode initialization - 5 vertical modes (Kitade, 1983);

(t) physical initialization (Krishnamurti et al. 1991); 


\section{REFERENCES}

Bengtsson, L., M. Botzet and M. Esch, 1995. Hurricanetype vortices in a general circulation model. Tellus 47A, 175-196.

Bengtsson, L., M. Botzet and M. Esch, 1996. Will greenhouse gas-induced warming over the next 50 years lead to higher frequency and greater intensity of hurricanes? Tellus 48A, 57-73.

Broccoli, A. J. and S. Manabe, 1990. Can existing climate models be used to study anthropogenic changes in tropical cyclone climate? Geophysical Research Letters 17, 1917-1920.

Businger, J. A., J. C. Wyngard, Y. Izumi and E. F. Bradley, 1971. Flux profile relationship in the atmospheric surface layer. J. Atmos. Sci. 28, 181-189.

Cess, R. D., M.-H. Zhang, G. L. Potter, H. W. Barker, R. A. Colman, D. A. Dazlich, A. D. Del Genio, M. Esch, J. R. Fraser, V. Galin, W. L. Gates, J. J. Hack, W. J. Ingram, J. T. Kiehl, A. A. Lacis, H. Le Treut, Z.-X. Li, X.-Z. Liang, J.-F. Mahfouf, B. J. McAvaney, V. P. Meleshko, J.-J. Morcrette, D. A. Randall, E. Roeckner, J.-F. Royer, A. P. Soklev, P. V. Sporyshev, K. E. Taylor, W.-C. Wang and R. T. Wetherald, 1993. Uncertainties of carbon dioxide radiative forcing in atmospheric general circulation models. Science 262, 1252-1255.

Cubasch, U., K. Hasselmann, H. Hoeck, E. MaierReimer, U. Mikolajewicz, B. D. Santer and R. Sausen, 1992. Transient greenhouse warming computations with a coupled ocean-atmosphere model. Climate Dyn. 8, 55-69.

Emanuel, K. A. 1986. An air-sea interaction theory for tropical cyclones. part I: Steady state maintenance. J. Atmos. Sci. 43, 585-604.

Emanuel, K. A. 1987. The dependence of hurricane intensity on climate. Nature. 326, 483-485.

Emanuel, K. A. 1988. Toward a general theory of hurricanes. American Scientist XX, 371-379.

Emanuel, K. A. 1991. The theory of hurricanes. Annu. Rev. Fluid Mech. 23, 179-196.

Emanuel, K. A. 1993. The physics of tropical cyclogenesis over the eastern Pacific. Tropical Cyclone Disasters 136-142.

Gray, W. M. 1968. Global view of the origin of tropical disturbances and storms. Mon. Wea. Rev. 96, 669-700.

Gray, W. M. 1988. Environmental influences on tropical cyclones. Aust. Met. Mag. 36, 127-139.

Haarsma, R. J., J. F. B. Mitchell and C. A Senior, 1993. Tropical disturbances in a GCM. Climate Dynamics 8, 247-257.

Harshvardan and T. G. Corsetti, 1984. Long-wave parameterization for the UCLA/GLAS GCM. NASA Tech. Memo. 86072, Goddard Space Flight Center, Greenbelt, MD 20771, USA, pp. 1-52.

Kanamitsu, M. 1975. On numerical prediction over a global tropical belt. Report No.75-1, Dept. of Met- eorology, Florida State University, Tallahassee, Florida 32306, pp. 1-282.

Kanamitsu, M., K. Tada, K. Kudo, N. Sato and S. Isa, 1983. Description of the JMA operational spectral model. J. Met. Soc. Japan 61, 812-828.

Kitade, T. 1983. Nonlinear normal mode initialization with physics. Mon. Wea. Rev. 111, 2194-2213.

Krishnamurti, T. N., S. Low-Nam and R. Pasch, 1983. Cumulus parameterization and rainfall rates II. Mon. Wea. Rev. 111, 816-828.

Krishnamurti, T. N. and D. Oosterhof, 1989a. Prediction of the Life Cycle of a Super-typhoon with a High Resolution Global Model. Bulletin of the American Meteorological Society 70, 1218-1230.

Krishnamurti, T. N., D. Oosterhof and N. Dignon, 1989b. Hurricane prediction with a high resolution global model. Mon. Wea. Rev. 117, 631-669.

Krishnamurti, T. N., H. S. Bedi, K. S. Yap, D. Oosterhof and G. Rohaly, 1992. Recurvature dynamics of a typhoon. Meteorology and Atmospheric Physics 50, 105-126.

Krishnamurti, T. N., H. S. Bedi and K. Ingles, 1993. Physical initialization using SSM/I rain rates. Tellus 45A 247-269.

Krishnamurti, T. N., H. S. Bedi, D. Oosterhof and V. Hardiker, 1994a. The formation of hurricane Frederic of 1979. Mon. Wea. Rev. 122, 1050-1074.

Krishnamurti, T. N., D. Oosterhof and D. Sukawat, 1994b. Numerical prediction of a Bangladesh tropical cyclone. Taiwan Journal of Atmosphere and Oceans 5, 245-276.

Krishnamurti, T. N., S. K. R. Bhowmik, D. Oosterhof G. Rohaly and N. Surgi, 1995a. Mesoscale signatures within the Tropics generated by physical initialization. Mon. Wea. Rev. 123, 2771-2790.

Krishnamurti, T. N., H. S. Bedi, G. D. Rohaly, M. Fulakeza, D. Oosterhof and K. Ingles, 1995b. Seasonal monsoon forecast for the years 1987 and 1988. Global and Planetary Change 10, 79-95.

Krishnamurti, T. N., H. S. Bedi, G. D. Rohaly and D. Oosterhof, 1996. Partitioning of the seasonal simulation of a monsoon climate. Mon. Wea. Rev. 124, 1499-1519.

Lacis, A. A. and J. E. Hansen, 1974. A parameterization of the absorption of solar radiation in the earth's atmosphere. J. Atmos. Sci. 31, 118-133.

Louis, J. F. 1979. A parametric model of vertical eddy fluxes in the atmosphere. Boundary Layer Meteorology 17, 187-202.

Manabe, S. and R. J. Stouffer, 1994. Multiple century response of a coupled ocean-atmosphere model to an increase of atmospheric carbon dioxide. J. Clim. 7, 5-28.

Sadler, J. C. and B. E. Harris, 1970. The mean tropospheric circulation and cloudiness over the southeast Asia and neighboring areas. Scientific Rept. 1, pp. 1-38.

Tellus 50A (1998), 2 
Tiedke, M. 1984. The sensitivity of the time-mean largescale flow to cumulus convection in the ECMWF model. Workshop on convection in large-scale numerical models. ECMWF, 28 Nov.-1 Dec. 1983, 297-316.

Tsutsui, J. and A. Kasahara, 1996. Simulated tropical cyclones using the National Center for Atmospheric
Research community climate model. J. Geophys. Res. 101, 15013-15032.

Wallace, J. M., S. Tibaldi and A. J. Simmons, 1983. Reduction of systematic forecast errors in the ECMWF model through the introduction of envelope orography. Quart. J. Roy. Met. Soc. 109, 683-718.

Tellus 50A (1998), 2 